\title{
Calcium-dependent modulation of the cardiac repolarization
}

\author{
PhD Thesis
}

Norbert Nagy, MSc

Department of Pharmacology and Pharmacotherapy University of Szeged

Szeged

Hungary 


\section{STUDIES RELATED TO THE THESIS}

I. Norbert Nagy, Viktória Szüts, Zoltán Horváth, György Seprényi, Attila S. Farkas', Károly Acsai, János Prorok, Miklós Bitay, Attila Kun, János Pataricza, Julius Gy. Papp, Péter P. Nánási, András Varró, András Tóth

Does small-conductance calcium-activated potassium channel contribute to cardiac repolarization?

J. of Molecular and Cellular Cardiology, 2009, 47:656-63

IF.: 5,05

II. Norbert Nagy, Károly Acsai, Attila S. Farkas, Norbert Jost, Péter P. Nánási, Julius G. Papp, András Varró, András Tóth

$\left[\mathrm{Ca}^{2+}\right]_{\mathrm{i}}$-induced augmentation of the inward rectifier potassium current $\left(\mathrm{I}_{\mathrm{K} 1}\right)$ in canine and human ventricular myocardium

Ready for submission

III. Farkas AS, Acsai K, Nagy N, Tóth A, Fülöp F, Seprényi G, Birinyi P, Nánási PP, Forster T, Csanády M, Papp JG, Varró A, Farkas A.

$\mathrm{Na}(+) / \mathrm{Ca}(2+)$ exchanger inhibition exerts a positive inotropic effect in the rat heart, but fails to influence the contractility of the rabbit heart

Br. J. Pharmacology, 2008, 154:256-7

IF.: 4,9

\section{OTHER STUDIES}

I. Acsai K, Kun A, Farkas AS, Fülöp F, Nagy N, Balázs $M$, Szentandrássy N, Nánási PP, Papp JG, Varró A, Tóth A.

Effect of partial blockade of the $\mathrm{Na}(+) / \mathrm{Ca}(2+)$-exchanger on $\mathrm{Ca}(2+)$ handling in isolated rat ventricular myocytes

Eur. J. Pharmacology, 2007, 576:1-6.

IF.: 2,52

II. Birinyi P, Tóth A, Jóna I, Acsai K, Almássy J, Nagy N, Prorok J, Gherasim I, Papp Z, Hertelendi Z, Szentandrássy N, Bányász T, Fülöp F, Papp JG, Varró A, Nánási PP, Magyar $J$.

The $\mathrm{Na}^{+} / \mathrm{Ca}^{2+}$ exchange blocker SEA0400 fails to enhance cytosolic $\mathrm{Ca}^{2+}$ transient and contractility in canine ventricular cardiomyocytes

Cardiovascular Research, 2008, 78:476-84

IF.: 6,127

III. János Prorok, Péter P. Kovács, Attila A. Kristóf, Norbert Nagy, Dóra Tombácz, Judit S. Tóth, Balázs Ördög, Norbert Jost, László Virág, Julius G. Papp, András Varró, András Tóth, Zsolt Boldogköi

Herpesvirus-mediated delivery of a genetically encoded fluorescent $\mathrm{Ca}^{2+}$ sensor to canine cardiomyocytes

J. of Biomedicine and Biotechnology, 2009, 2009:361795

IF.: 1,92 


\begin{abstract}
S
I. Prorok J., Nagy N., Kormos A., Acsai K., Papp J.Gy., Varró A., Tóth A. A $\mathrm{Na}^{+} / \mathrm{Ca}^{\frac{2+}{2+}}$ cseremechanizmust blokkoló SEA0400 hatása intracelluláris szívizomsejtekben.

Cardiol. Hungarica, 2008, 38. Suppl.B: B20

II. Nagy N, Szüts V, Horváth Z, Farkas A, Acsai K, Papp JGy, Varró A, Tóth A Az alacsony konduktanciájú kalcium-aktivált kálium áram nem befolyásolja a repolarizációt fiziológiás körülmények között patkány- és kutya szívben.

Cardiol. Hungarica, 2008, 38: Suppl.B: B65

III. Nagy N, Acsai K, Farkas A, Papp JGy, Varró A, Tóth A

$\mathrm{Az}$ I $\mathrm{K}_{\mathrm{K}}$-áram $\left[\mathrm{Ca}^{2+}\right]_{\mathrm{i}}$-függő módon szabályozza a repolarizációs tartalékot kutya szívizomban. (The dynamic regulation of $\mathrm{I}_{\mathrm{K} 1}$ by increased $\left[\mathrm{Ca}^{2+}\right]_{\mathrm{i}}$ amplifies repolarization reserve in dog ventricular myocardium)

Cardiol. Hungarica, 2010, 40: Suppl.G: G46

IV. Nagy N, Acsai K, Farkas A, Papp JGy, Varró A, Tóth A

Dynamic regulation of $\mathrm{I}_{\mathrm{K} 1}$ by increased $\left[\mathrm{Ca}^{2+}\right]_{\mathrm{i}}$ enhances repolarization reserve in dog myocardium

Cardiovascular Research, 2010, 87: Suppl.1: S62-S62

V. Nagy N, Szentandrássy N, Szebeni Á, Kormos A, Acsai K, Nánási P, Papp JGy, Varró A, Tóth A

A nátrium-kalcium exchanger gátlás csökkenti a nátrium indukált kalcium overload-ot kutya szívizomban. (Inhibition of sodium-calcium exchanger reduces the sodium induced calcium overload in canine myocardium)

Cardiol. Hungarica, 2011, 41: Suppl.F: F38-F39
\end{abstract}




\section{ACRONYMS AND ABREVIATIONS}

$\left[\mathbf{C a}^{2+}\right]_{\mathbf{i}}$ : intracellular $\mathrm{Ca}^{2+}$

AP: action potential

APD: action potential duration

ATP: adenosine-triphosphate

CaM: calmodulin

CaMKII: $\mathrm{Ca}^{2+}$-dependent calmodulin-kinase II

cAMP: cyclic adenosine-monophosphate

CaT: $\mathrm{Ca}^{2+}$ transient

CDF: $\mathrm{Ca}^{2+}$ dependent facilitation

CDI: $\mathrm{Ca}^{2+}$ dependent inactivation

CICR: $\mathrm{Ca}^{2+}$ induced $\mathrm{Ca}^{2+}$ release

ECC: excitation contraction coupling

$\mathbf{I}_{\mathbf{C a L}}$ : L-type $\mathrm{Ca}^{2+}$ current

$\mathbf{I}_{\mathbf{C l}(\mathbf{C a})}$ or $\mathbf{I}_{\text {to2: }} \mathrm{Ca}^{2+}$ dependent $\mathrm{Cl}^{-}$current

$\mathbf{I}_{\mathbf{K}(\mathbf{C a}):}: \mathrm{Ca}^{2+}$ dependent $\mathrm{K}^{+}$current

$\mathbf{I}_{\mathbf{K} 1:}$ inward rectifier $\mathrm{K}^{+}$current

$\mathbf{I}_{\mathbf{K r}}$ : rapid component of the delayed rectifier $\mathrm{K}^{+}$current

$\mathbf{I}_{\mathbf{K s}}$ : slow component of the delayed rectifier $\mathrm{K}^{+}$current

$\mathbf{I}_{\mathrm{Na}}: \mathrm{Na}^{+}$current

$\mathbf{I}_{\text {SK }}$ : small-conductance $\mathrm{Ca}^{2+}$ activated $\mathrm{K}^{+}$current

$\mathbf{I}_{\mathbf{t o}}$ : transient outward $\mathrm{K}^{+}$current

NCX: $\mathrm{Na}^{+}-\mathrm{Ca}^{2+}$ exchanger

NKE: $\mathrm{Na}^{+}-\mathrm{K}^{+}$ATPase

RyR: ryanodine receptor

SERCA: sarcoplasmic reticulum $\mathrm{Ca}^{2+}$ ATPase 


\section{TABLE OF CONTENTS}

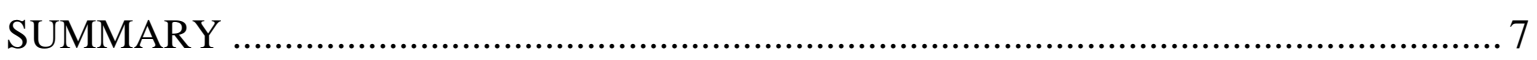

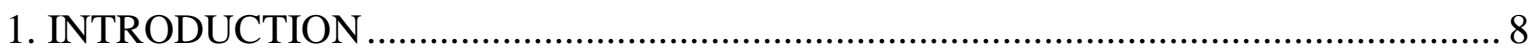

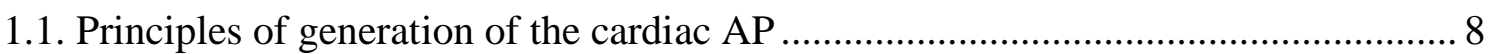

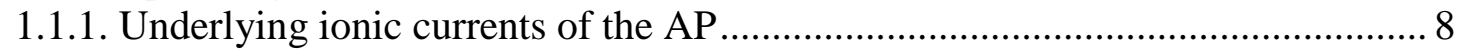

1.1.2. Significance of the cardiac repolarization reserve........................................... 10

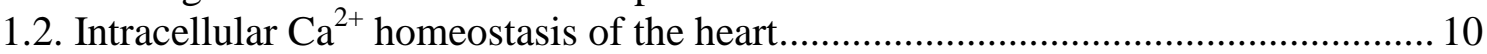

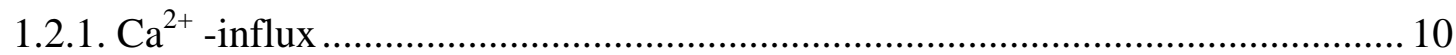

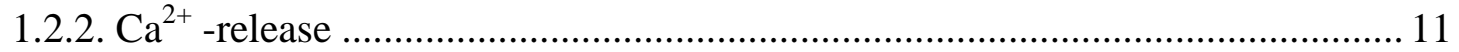

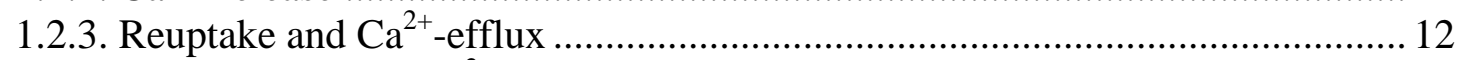

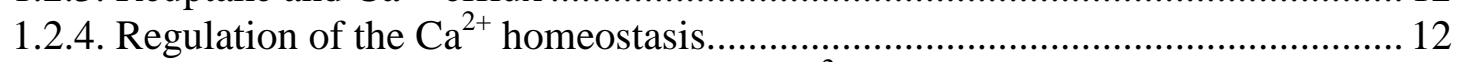

1.3. Interactions between AP repolarization and $\mathrm{Ca}^{2+}$ handling.................................... 13

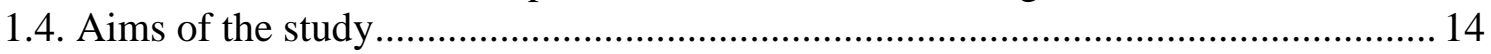

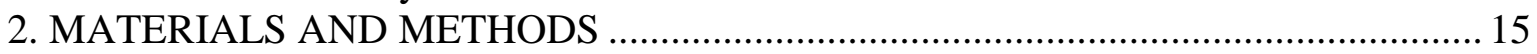

$2.1 \quad$ Ethical considerations.................................................................................. 15

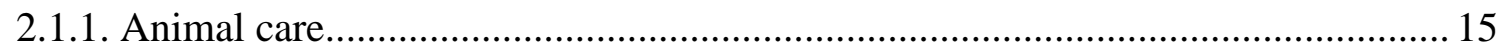

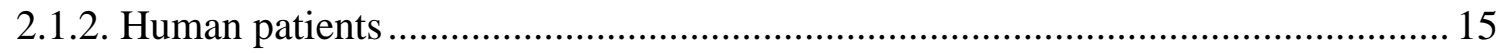

2.2. Isolation of rat and canine and rabbit ventricular myocytes.................................... 15

2.3. Recording of APs in multicellular cardiac preparations......................................... 16

2.4. Determination of ionic currents in single mammalian ventricular cells.................... 17

2.4.1. Apamin sensitive current measured by the whole cell patch clamp technique . 18

2.4.2. Apamin-sensitive current measured by perforated patch clamp technique....... 18

2.4.3. $\mathrm{Ca}^{2+}$ dependency of $\mathrm{I}_{\mathrm{K} 1}$ measured by whole cell patch clamp method ............... 18

2.5. Recording of CaTs in field-stimulated canine and rat ventricular tissues................. 19

2.6. Molecular biological techniques......................................................................... 19

2.6.1. Protein isolation and Western blot analysis..................................................... 19

2.6.2. Immunohistochemistry and confocal microscopy ………………………........ 20

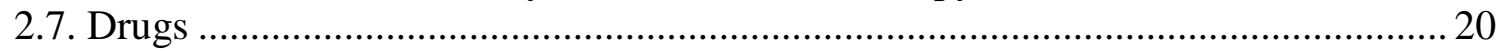

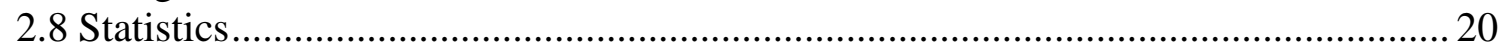

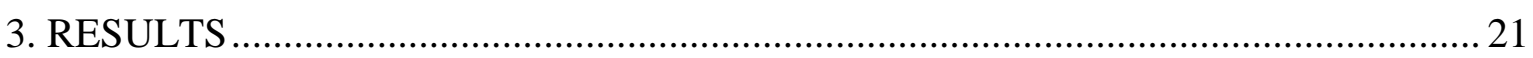

3.1. Functional analysis of the cardiac SK channels ................................................... 21

3.1.1. Expression of SK2 channel protein in canine and rat ventricular myocardium 21

3.1.2. Measurements of intracellular CaTs ................................................................ 22

3.1.3. Effect of apamin on APs recorded from canine, rat, and human multicellular cardiac preparations ............................................................................................ 23

3.1.4. Effect of $1 \mu \mathrm{M}$ SEA0400 on ventricular AP and CaT.....................................2 25

3.1.5. Effect of apamin on ion currents in single canine and rat ventricular cells....... 27

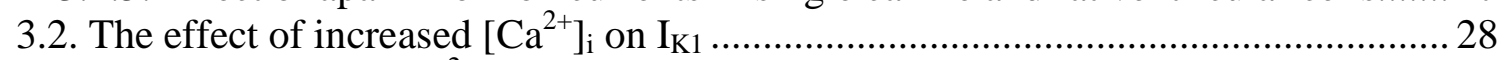

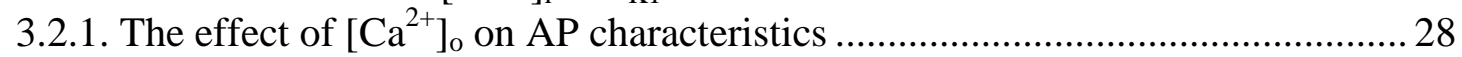

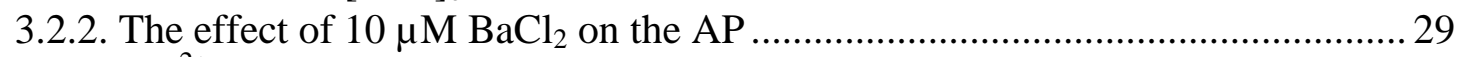

3.2.3. $\left[\mathrm{Ca}^{2+}\right]_{\mathrm{i}}$ dependent effect of $\mathrm{I}_{\mathrm{K} 1}$ on repolarization reserve..................................... 30

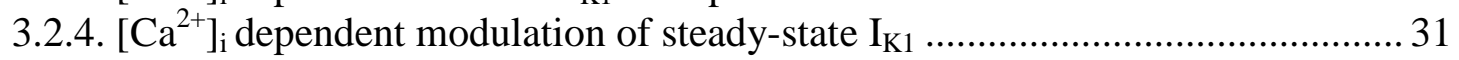

3.2.5. Determination of the instantaneous $\mathrm{I}_{\mathrm{K} 1}$ current during an $\mathrm{AP}$............................ 31

3.2.6. Effect of dynamic increase of $\left[\mathrm{Ca}^{2+}\right]_{\mathrm{i}}$ on steady state $\mathrm{I}_{\mathrm{K} 1} \ldots \ldots \ldots \ldots \ldots \ldots \ldots \ldots \ldots \ldots . . . . . . . . . . . . . . . .32$

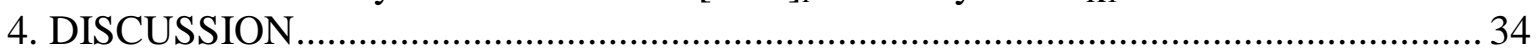

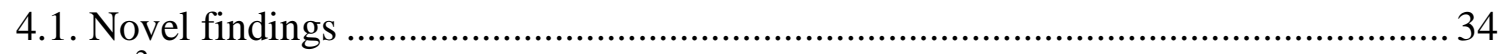

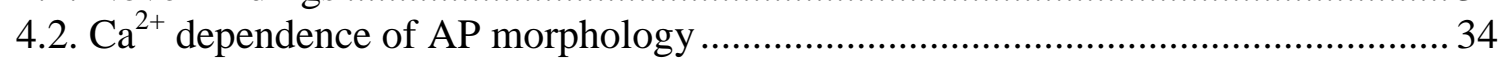

4.2.1. Depolarizing currents ............................................................................... 34 


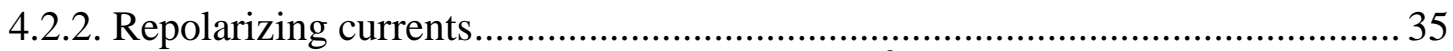

4.2.2.1. Direct link between repolarization and $\mathrm{Ca}^{2+}$ handling .............................. 36

4.2.2.2. Indirect interactions via main repolarizing currents $\left(\mathrm{I}_{\mathrm{to}}, \mathrm{I}_{\mathrm{Kr}}, \mathrm{I}_{\mathrm{Ks}}\right)$............. 37

4.3. Are there functioning SK channels in mammalian myocardium?............................ 38

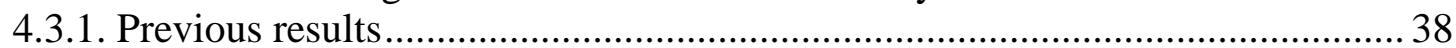

4.3.2. Has any role SK current in cardiac repolarization? ...................................... 38

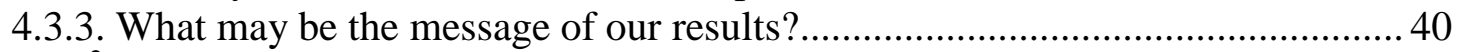

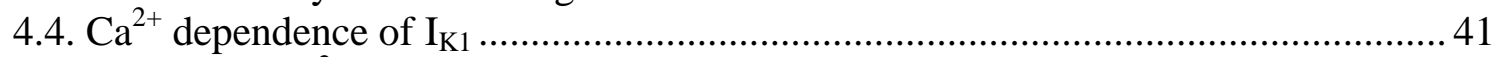

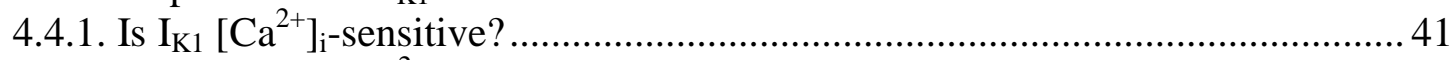

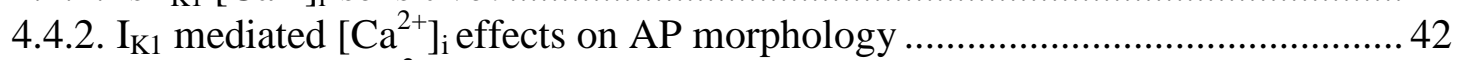

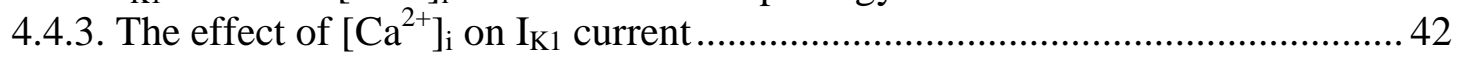

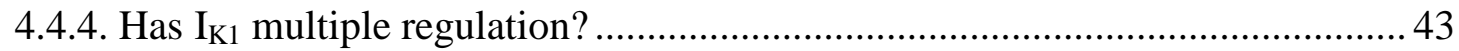

4.4.5. What may be the message of our results? ........................................................ 44

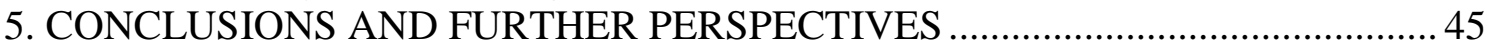

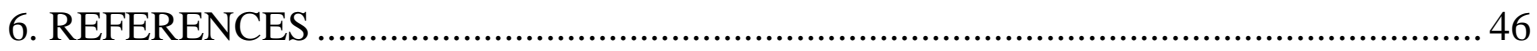

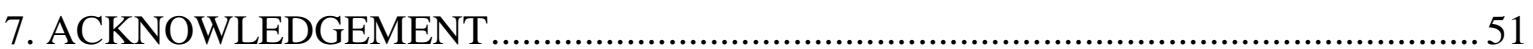




\section{SUMMARY}

Normal heart function and optimal repolarization of the cardiac action potential (AP) is to high extent subject to synchronized activity of sarcolemmal $\mathrm{K}^{+}$channels, expressed in both ventricular and atrial myocardium, largely contributing to regulation of the resting potential, the pacemaker activity, and the shape and duration of the AP (APD). Clinical observations and experimental studies in both isolated cardiomyocytes and multicellular preparations provided firm evidence for the sensitivity of several major $\mathrm{K}^{+}$currents and the corresponding ion channels to shifts in intracellular $\mathrm{Ca}^{2+}$ concentration $\left(\left[\mathrm{Ca}^{2+}\right]_{\mathrm{i}}\right)$. Direct regulation via interaction between $\left[\mathrm{Ca}^{2+}\right]_{i}$ and the channel protein or indirect modulation via $\mathrm{Ca}^{2+}$ signaling pathways of these currents may have implications to mechanical and electrical performance of the heart, and its physiological adaptation to altered load. Nonetheless, it may also lead to severe cardiac dysfunction, if $\left[\mathrm{Ca}^{2+}\right]_{i}$ handling is significantly disturbed, as is the case in a variety of pathological conditions.

The primary aims of our studies, summarized in this thesis were 1) to attempt to clarify the apparently unsolved question of the physiological role of the cardiac small conductance $\mathrm{Ca}^{2+}$-activated $\mathrm{K}^{+}(\mathrm{SK})$ channels and, since data in literature, regarding the direction and nature of this modulation are also highly controversial: 2) to investigate in detail the possible $\mathrm{Ca}^{2+}$-dependence of the inward rectifier $\mathrm{K}^{+}$current $\left(\mathrm{I}_{\mathrm{K} 1}\right)$.

Our results demonstrate that in rat, dog and human ventricular cells - though present SK2 channels seem to be inactive and do not contribute to AP repolarization, at least under normal physiological conditions. We also provide evidence that in canine myocardium the APD shortening effect of $\left[\mathrm{Ca}^{2+}\right]_{i}$ rise is at least partially mediated by $\left[\mathrm{Ca}^{2+}\right]_{\mathrm{i}}$-dependent augmentation of $\mathrm{I}_{\mathrm{K} 1}$. 


\section{INTRODUCTION}

\subsection{Principles of generation of the cardiac AP}

The electric integrity of the heart is an essential requirement for its synchronized activity and its adaptation to various external conditions. A crucial point of the beat-to-beat regulation of the heart is the fine-tuning of the APD, achieved primarily by a strict control of the repolarizing $\mathrm{K}^{+}$currents. In the past decades and also recently, a number of studies provided evidence that physiological regulation of the repolarization process, as well as the corresponding ionic currents, is a complex mechanism and may be substantially modulated by $\mathrm{Ca}^{2+}$ signaling pathways. Considering that the $\mathrm{Ca}^{2+}$ cycle of the heart is also subject to large variations under different conditions (i.e. frequency changes, adrenergic modulation, a number of severe cardiac diseases) a dynamic interrelationship should exist between intracellular $\mathrm{Ca}^{2+}$ handling and AP, which may substantially influence the normal cardiac adaptation or in certain conditions may lead to arrhytmia propensity. Therefore, a detailed analysis of this relationship may significantly improve our currently limited understanding on the mechanisms of physiological and pathological alterations of cardiac repolarization, as well as substantially facilitates the development of new pharmacological strategies.

\subsubsection{Underlying ionic currents of the AP}

The cardiac AP reflects coordinated activity of multiple ion channels that open, close and/or inactivate with different kinetics (see Fig.1.). Upon activation cardiomyocytes are depolarized by a rapid inflow of $\mathrm{Na}^{+}$ions generating a large and fast inward $\mathrm{Na}^{+}$current $\left(\mathrm{I}_{\mathrm{Na}}\right)$. $\mathrm{I}_{\mathrm{Na}}$ not only defines the rapid upstroke of the AP (phase 0 ) but has also primary role in defining the velocity of impulse propagation through the heart. The initial depolarization of the AP is followed by a transient repolarization (phase 1) mainly governed by the transient outward current $\left(\mathrm{I}_{\mathrm{to}}\right)$. In this section of the AP, the $\mathrm{Ca}^{2+}$-activated $\mathrm{Cl}^{-}$current $\left(\mathrm{I}_{\mathrm{Cl}(\mathrm{Ca})}\right.$ or $\left.\mathrm{I}_{\mathrm{to} 2}\right)$ is also suggested to contribute to the transient repolarization. The rapid upstroke of the AP activates the L-type $\mathrm{Ca}^{2+}$ current $\left(\mathrm{I}_{\mathrm{CaL}}\right)$ and also several crucial $\mathrm{K}^{+}$ currents involved in the repolarization: i.e. the rapid and slow components $\left(\mathrm{I}_{\mathrm{Kr}}\right.$ and $\left.\mathrm{I}_{\mathrm{Ks}}\right)$ of the delayed rectifier $\mathrm{K}^{+}$current and the inward rectifier $\mathrm{K}^{+}$current $\left(\mathrm{I}_{\mathrm{K} 1}\right)$. During a period of time $\mathrm{I}_{\mathrm{CaL}}$ opposes the outward repolarizing currents, establishing a nearly isoelectric plateau phase (phase 2) of the AP. The duration of the plateau phase has important role in controlling the amount of the $\mathrm{Ca}^{2+}$ influx. The $\mathrm{Ca}^{2+}$ influx has crucial role in initializing the 
intracellular $\mathrm{Ca}^{2+}$ cycle leading to contraction of the cell. When $\mathrm{Ca}^{2+}$ channels begin to close the outward currents gradually overcame $\mathrm{I}_{\mathrm{CaL}}$, enabling fast repolarization of the AP (phase 3), governed by cooperative function of $\mathrm{I}_{\mathrm{Ks}}, \mathrm{I}_{\mathrm{Kr}}$, and $\mathrm{I}_{\mathrm{K} 1}$. The terminal repolarization (phase 4) of the AP, as well as the resting membrane potential is primarily controlled by the $\mathrm{I}_{\mathrm{K} 1}$.

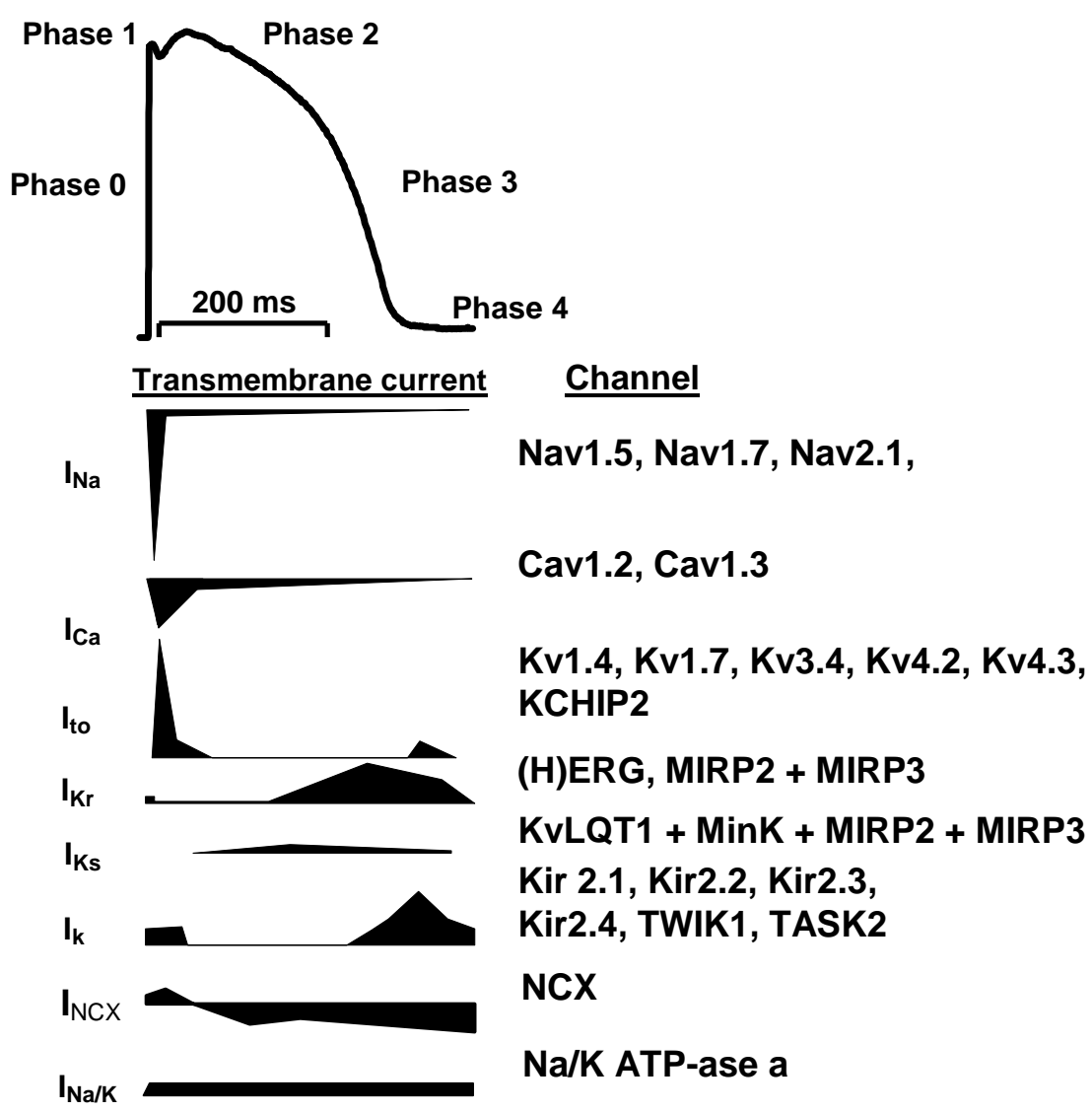

Fig.1. The ventricular $A P$ and corresponding ion currents. The upper panel shows a representative ventricular AP and phases of the AP kinetics. The underlying ionic currents are shown in the left side of the lower panel in time-match with the AP. The inward currents are depicted as downward deflections. Note that the amplitudes of the currents are not proportional with each other. The channel proteins carrying the current are marked at right side of the lower panel (modified from Ravens et al. [1])

Several electrogenic ionic pumps and exchangers may also substantially contribute to shaping of the AP. The electrogenic $\mathrm{Na}^{+} / \mathrm{K}^{+}$ATPase (NKE) has a pivotal role in setting the uneven distribution of $\mathrm{Na}^{+}$and $\mathrm{K}^{+}$ions between the intra- and extracellular spaces, thus enabling the excitability of the cardiomyocytes. The $\mathrm{Na}^{+} / \mathrm{Ca}^{2+}$ exchanger (NCX), which is also electrogenic, may also contribute to the AP. Since the equilibrium potential of the NCX lies in the range of AP, both inward and outward currents can be generated. However the exact role of the NCX during an AP is not yet fully elucidated. 


\subsubsection{Significance of the cardiac repolarization reserve}

The concept and terminology of the repolarization reserve was introduced by Roden in 1998, based merely on clinical observations [2]. The principle of the repolarization reserve is a redundancy of the repolarization process, i.e. loss of one repolarizing current may not lead to excessive AP lengthening, since other unimpaired $\mathrm{K}^{+}$channels may provide sufficient repolarizing capacity ([3-6]). Therefore, it has critical importance in stabilizing the APD, refractoriness and conduction of the electric impulses. Furthermore, it restricts excessive AP lengthening caused by impaired channel function, e.g. in LQT's, extreme bradycardia, hypokalaemia, hypotiroidism, diabetes mellitus, drug exposure, etc [7]. The repolarization reserve has also important role in decreasing the transmural dispersion of the repolarization, thus preventing cardiac arrhythmias [8]. The key players of the reserve are $\mathrm{I}_{\mathrm{Kr}}, \mathrm{I}_{\mathrm{Ks}}, \mathrm{I}_{\mathrm{K} 1}$, and presumably $\mathrm{I}_{\mathrm{to}}$ ([3-6]. These repolarizing currents play a critical role in normal myocardial function, furthermore, the majority of life-threatening arrhythmias are known to derive from repolarization abnormalities. Therefore, better understanding of the pathomechanisms leading to AP abnormalities, and the development of novel strategies to treat arrhythmias require much more detailed knowledge of the repolarization mechanisms, including all its determinants (e.g.: $\left[\mathrm{Ca}^{2+}\right]_{\mathrm{i}}$ ).

\subsection{Intracellular $\mathrm{Ca}^{2+}$ homeostasis of the heart}

The purpose of the excitation-contraction (ECC) coupling of the heart is to provide effective and in the same time adaptive cardiac output by activation of the myofilaments. The ECC is governed by a highly complex mechanism initiated by depolarization of the sarcolemma and finalized by the contraction-relaxation cycle. $\mathrm{Ca}^{2+}$ has a central role in ECC, since $\mathrm{Ca}^{2+}$ ions entering the cell from the extracellular space $\left(\mathrm{Ca}^{2+}\right.$-influx $)$ trigger a substantially larger $\mathrm{Ca}^{2+}$ release from the sarcoplasmic reticulum (SR). The transient $\left[\mathrm{Ca}^{2+}\right]_{\mathrm{i}}$ increase $\left(\mathrm{Ca}^{2+}\right.$ transient, $\left.\mathrm{CaT}\right)$ is terminated by both $\mathrm{Ca}^{2+}$ reuptake to the $\mathrm{SR}$ (via the activity of the SR $\mathrm{Ca}^{2+}$ pump, SERCA2a), and $\mathrm{Ca}^{2+}$ extrusion (efflux) from the cell (primarily via the forward mode activity of the NCX) (see Fig. 2).

\subsection{1. $\mathrm{Ca}^{2+}$-influx}

Two classes of $\mathrm{Ca}^{2+}$ channels ( $\mathrm{T}$ and $\mathrm{L}$ types) exist in cardiac myocytes. T-type channels are practically not present in ventricular myocytes, while L-type channels are abundantly expressed, primarily at the sarcolemmal SR junctions. During depolarization Ltype voltage dependent $\mathrm{Ca}^{2+}$ channels exhibit large conductance. The relatively small $\mathrm{Ca}^{2+}$ 
ion flux which enters the cell is able to release a substantially larger $\mathrm{Ca}^{2+}$ ion flux from the $\mathrm{SR}$, via triggering the ryanodine receptors (RyR). This mechanism is called ' $\mathrm{Ca}^{2+}$-induced $\mathrm{Ca}^{2+}$ release' (CICR). A minor flux of $\mathrm{Ca}^{2+}$ ions pass in the cell via the reverse mode activity of NCX, counterbalanced by $\mathrm{Na}^{+}$extrusion. The amount of $\mathrm{Ca}^{2+}$ influx is primarily controlled via the magnitude and time course of the $\mathrm{SR} \mathrm{Ca}^{2+}$ release by a simple negative feed-back mechanism, termed as $\mathrm{Ca}^{2+}$ dependent inactivation [9-11].

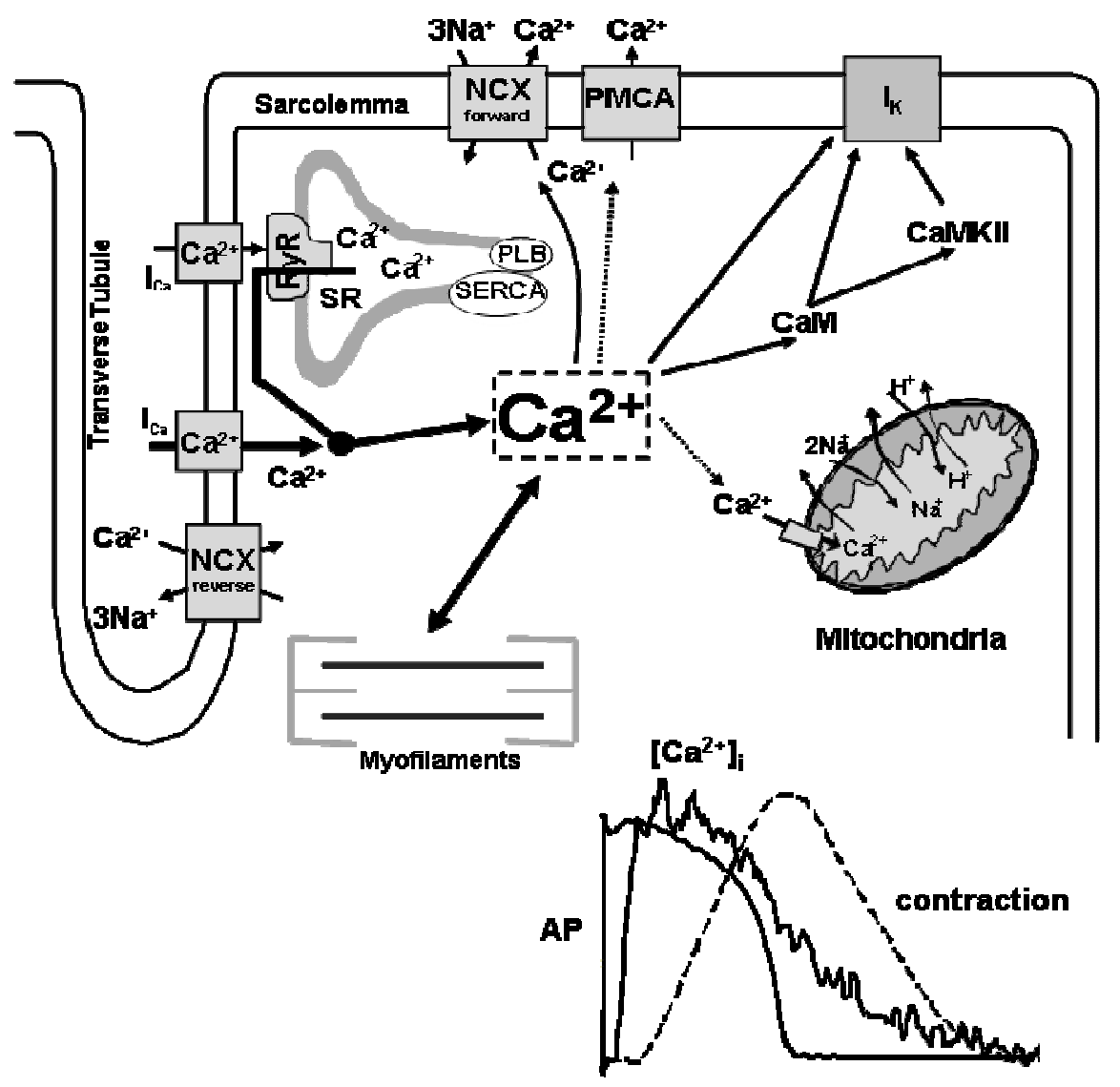

Fig.2. Intracellular $\mathrm{Ca}^{2+}$ homeostasis of the cardiac cell. The upper panel shows the main routes of the $\mathrm{Ca}^{2+}$ movements of the cell, and the potential direct and indirect regulative roles of the $\mathrm{Ca}^{2+}$ on $\mathrm{K}^{+}$channels. The $\mathrm{I}_{K}$ in this case confines the main $\mathrm{K}^{+}$channels of the heart $\left(I_{t o}, I_{K r}, I_{K s}, I_{K 1}, I_{S K}\right)$. The lower panel compares the time courses of the cardiac AP, CaT, and contraction (modified from Bers [12])

\subsection{2. $\mathrm{Ca}^{2+}$-release}

The large amount of $\mathrm{Ca}^{2+}$ stored in the $\mathrm{SR}$ is mostly bounded to a $\mathrm{Ca}^{2+}$ binding protein called calsequestrin. When the trigger $\mathrm{Ca}^{2+}$ reaches the RyRs, their conductance significantly increases, enabling the release of the stored $\mathrm{Ca}^{2+}$. This can be monitored by optical (fluorometric) techniques. Since cardiac myocytes consist of several intracellular compartments, the rise in $\left[\mathrm{Ca}^{2+}\right]_{\mathrm{i}}$ is highly inhomogeneous. From this point three important 
compartments can be distinguished: (i) the dyadic space (fuzzy space), located between the terminal cistern of the SR and inner side of the sarcolemma (ii) the submembrane area, a narrow region under the sarcolemma, (iii) and the bulk cytosol which is the largest compartment of the intracellular space, located around the contractile proteins. Therefore, the $\left[\mathrm{Ca}^{2+}\right]_{\mathrm{i}}$ at the myofilaments is determined by the amount of $\mathrm{Ca}^{2+}$ released from the SR, and the amount of $\mathrm{Ca}^{2+}$ diffused from the fuzzy space. It is important to note that during the $\mathrm{CaT}$ the $\left[\mathrm{Ca}^{2+}\right]_{\mathrm{i}}$ in the dyadic space reaches considerably larger magnitude and declines much faster compared to that in the bulk cytosol. Consequently the ion channels and transporters are located in the plasma membrane, they are subject to markedly larger (and faster) beat-to-beat $\mathrm{Ca}^{2+}$ fluctuations, than can be measured in the cytosol by the conventional fluorometric technique [12].

\subsubsection{Reuptake and $\mathrm{Ca}^{2+}$-efflux}

Sequestration of the released $\mathrm{Ca}^{2+}$ and stabilization of the diastolic $\left[\mathrm{Ca}^{2+}\right]$ between contractions is crucial in the regulation of the beat-to-beat $\mathrm{Ca}^{2+}$ balance under varying conditions. The majority of the systolic $\mathrm{Ca}^{2+}$ increase is reuptaken into the $\mathrm{SR}$ by its $\mathrm{Ca}^{2+}$ pump (SERCA2a). A much smaller amount of $\left[\mathrm{Ca}^{2+}\right]_{\mathrm{i}}$ is extruded from the cell, primarily via the forward activity of the NCX. In steady state during each cycle the released and reuptaken $\mathrm{Ca}^{2+}$, as well as the entered and extruded $\mathrm{Ca}^{2+}$ must be equal. The NCX, as a passive transporter, is governed by the intra-, and extracellular levels of the $\mathrm{Na}^{+}$and $\mathrm{Ca}^{2+}$ ions, and also depends on the actual value of the membrane potential. Based on the direction of the ion transport reverse and forward modes of operation can be distinguished. During reverse mode activity $\mathrm{Ca}^{2+}$ influx and an outward current (carried by $\mathrm{Na}^{+}$ions) can be observed, while during forward mode NCX activity $\mathrm{Ca}^{2+}$ is extruded and an inward $\mathrm{Na}^{+}$ current is generated. Since the operation of the NCX is electrogenic, under certain conditions it may generate significant ionic current in either direction. An ATP-dependent $\mathrm{Ca}^{2+}$ transporter, the $\mathrm{Ca}^{2+}$ pump of the plasma membrane (PMCA) may also extrude $\mathrm{Ca}^{2+}$, however its contribution to maintaining $\mathrm{Ca}^{2+}$ balance is much less important, and its role is suggested to be primarily restricted to fine tuning of the diastolic $\mathrm{Ca}^{2+}$ level [12-14].

\subsubsection{Regulation of the $\mathrm{Ca}^{2+}$ homeostasis}

Cardiac $\mathrm{Ca}^{2+}$ handling is tightly regulated by both intrinsic and extrinsic mechanisms. Intrinsic regulation is the autoregulation of $\left[\mathrm{Ca}^{2+}\right]_{i}$, achieved by a simple negative and/or positive feed-back of $\left[\mathrm{Ca}^{2+}\right]_{i}$ on $\mathrm{Ca}^{2+}$ influx and efflux, respectively. This mechanism 
always sets stable $\left[\mathrm{Ca}^{2+}\right]_{\mathrm{i}}$ level by fine tuning the $\mathrm{Ca}^{2+}$ content of the SR via balancing the $\mathrm{Ca}^{2+}$ influx and efflux at the same time. For example, under experimental conditions, when the $\left[\mathrm{Ca}^{2+}\right]_{\mathrm{i}}$ is close to the diastolic value (e.g.: after caffeine exposure), CaT is small, producing minimal inhibiting effect on the influx, and marginal enhancement on the efflux. Consequently, $\mathrm{Ca}^{2+}$ influx is far better favored than efflux and the cardiomyocyte is getting loaded with $\mathrm{Ca}^{2+}$. Following some beats the increasing $\mathrm{SR} \mathrm{Ca}^{2+}$ content permits larger $\mathrm{CaT}$, which in turn restricts influx and promotes efflux until transsarcolemmal $\mathrm{Ca}^{2+}$ fluxes are balanced. This process is an intrinsic property of $\mathrm{Ca}^{2+}$ homeostasis of the cardiac cell, and does not require any external (i.e. adrenergic) control $[9,11,15]$.

The extrinsic regulating mechanism is achieved by the neurohormonal system, which adjusts the activity of heart to meet the requirements of the body in various physiological or pathological situations (e.g. physical activity, stress, pregnancy, or several diseases etc.). This system acts primarily via the cAMP and protein kinase-A (PKA) signaling pathways following the binding of noradrenalin to $\beta 1$ receptors, and may cause multiple effects. The regulation is performed via phosphorylation of the L-type $\mathrm{Ca}^{2+}$ channels, RyR, SERCA2, and troponin, leading to increased $\mathrm{Ca}^{2+}$ influx and release, faster reuptake, and more effective contraction. Other signaling mechanisms via activation of the protein kinase-C (PKC) pathway also have important regulative role on various ionic currents [12].

\subsection{Interactions between $A P$ repolarization and $\mathrm{Ca}^{2+}$ handling}

Cardiac contraction is achieved by large elevation in $\left[\mathrm{Ca}^{2+}\right]_{\mathrm{i}}$, therefore sarcolemmal $\mathrm{K}^{+}$channels sense the beat-to-beat fluctuations in $\mathrm{Ca}^{2+}$ levels. The magnitude of the CaT shows large variability even in physiological conditions (during exercise, or emotional stress due to the adrenergic activation), furthermore in a variety of heart diseases (e.g.: heart failure, ischaemia/reperfusion injury, long-QT syndrome), where $\mathrm{Ca}^{2+}$ levels are also considerably influenced (increased or decreased) [16]. Therefore, it seems feasible that subsarcolemmal $\mathrm{Ca}^{2+}$ levels are able to modulate cardiac $\mathrm{K}^{+}$currents, thus could provide a further major mechanism to improve AP adaptation under various conditions.

Theoretically, $\left[\mathrm{Ca}^{2+}\right]_{\mathrm{i}}$-dependent modulation of a $\mathrm{K}^{+}$ion channel can be established either directly or indirectly, via the $\mathrm{Ca}^{2+}$-dependent calmodulin $(\mathrm{CaM})$, or the calmodulindependent protein kinase II (CaMKII). Nonetheless, the entire mechanism is probably more complicated, since shifts in $\mathrm{Ca}^{2+}$ levels are often the consequence of the activation of adrenergic pathways raising PKA and/or PKC. Since PKA and PKC may exert various effects (activation or inhibition) on $\mathrm{K}^{+}$currents, one may speculate that the actual effect on 
a given $\mathrm{K}^{+}$channel might be the result of multiple, simultaneously activated controlling pathways. In theory, the regulation of the repolarization process by $\mathrm{Ca}^{2+}$ signaling may have important role considering the following points:

$i$. Under normal conditions and heart rates, a $\mathrm{K}^{+}$channel may be dynamically modulated by alterations in subsarcolemmal $\mathrm{Ca}^{2+}$, thus contributing to fine tuning repolarization and APD.

ii. In large mammals, APD and $\left[\mathrm{Ca}^{2+}\right]_{\mathrm{i}}$ show parallel changes upon frequency adaptation, therefore the increase or decrease in $\left[\mathrm{Ca}^{2+}\right]_{\mathrm{i}}$ may substantially promote the prompt frequency adaptation of APD

iii. $\left[\mathrm{Ca}^{2+}\right]_{\mathrm{i}}$ mismanagement, frequently observed in cardiac diseases may significantly influence $\mathrm{K}^{+}$channel function.

\subsection{Aims of the study}

The primary goal of the present study was to elucidate a few aspects of the possible modulatory effect of changes in $\left[\mathrm{Ca}^{2+}\right]_{\mathrm{i}}$ on repolarization and to elucidate its functional consequences.

- First, we investigated the possible physiological role of the small conductance $\mathrm{Ca}^{2+}$ activated $\mathrm{K}^{+}$channels (SK-channels) in the repolarization process in rat, canine and human myocardium,

- Second, we attempted to elucidate the effect of $\left[\mathrm{Ca}^{2+}\right]_{i}$ rise on $I_{K 1}$. The possible consequences of this relationship on the cardiac repolarization reserve were also investigated. 


\section{MATERIALS AND METHODS}

\subsection{Ethical considerations}

\subsubsection{Animal care}

All studies were conducted in full accordance with the standards of the European Community guidelines on the care and use of laboratory animals. All experimental protocols were approved by the Ethical Committee for Protection of Animals in Research of the University of Szeged, Hungary (permit No. 54/1999 Oej).

\subsubsection{Human patients}

Undiseased hearts obtained from organ donors were explanted to obtain pulmonary and aortic valves for transplant surgery. Before cardiac explantation, the donor did not receive medication, except furosemide, dobutamine and plasma expanders. Investigations conform the principles outlined in the Declaration of Helsinki and all experimental protocols were approved by Regional and Institutional Human Medical and Biological Research Ethics Committee, University of Szeged, permit No. 717. (No. 63/97).

\subsection{Isolation of rat, canine and rabbit ventricular myocytes}

Adult male Sprague-Dawley rats, weighing 150-200 g, were retrogadely perfused for $5 \mathrm{~min}$ at $37{ }^{\circ} \mathrm{C}$ with Krebs-Henseleit solution (containing in $\mathrm{mM}: \mathrm{NaCl} 118.5, \mathrm{KCl} 4$, $\mathrm{CaCl}_{2} 2, \mathrm{MgSO}_{4} 1, \mathrm{NaH}_{2} \mathrm{PO}_{4} 1.2, \mathrm{NaHCO}_{3} 25$, and glucose 10 ; the $\mathrm{pH}$ of this solution was set to $7.35 \pm 0.05$ when saturated with mixture of $95 \% \mathrm{O}_{2}$ and $5 \% \mathrm{CO}_{2}$ ). Then, the superfusion was switched for $8 \mathrm{~min}$ to $\mathrm{Ca}^{2+}$-free Krebs-Henseleit solution. Finally, the perfusate was completed with $0.5 \mathrm{~g} / 1$ collagenase (Type I, Sigma), 0.5g/l hyaluronidase, $200 \mu \mathrm{M} \mathrm{CaCl} 2$, and the heart was perfused for further 7 minutes. At the end of the enzymatic dissociation process the left ventricular myocardium was minced and gently agitated. Freshly isolated cells were placed into storage-solution (containing in $\mathrm{mM}$ : $\mathrm{KOH}$ 89, glutamate 70 , taurine $15, \mathrm{KCl} 30, \mathrm{KH}_{2} \mathrm{PO}_{4}$ 10, HEPES $10, \mathrm{MgCl}_{2}$ 0.5, glucose 10 , EGTA 0.5, $\mathrm{pH}=7.3$ ) and kept at room temperature until used.

Single canine ventricular cells were obtained from hearts of adult mongrel dogs of either sex weighing 10-20 kg, using the "segment perfusion" technique. The animals were anaesthetized with an i.v. injection containing $30 \mathrm{mg} / \mathrm{kg}$ thiopental. After opening the chest 
the heart was removed and a segment of the left ventricular wall was perfused via the anterior descending coronary artery using a gravity flow Langendorff apparatus. The perfusate was modified MEM solution (Minimum Essential Medium Eagle, Joklik modification, Sigma, M-0518), supplemented with $1.2 \mathrm{mM} \mathrm{CaCl}_{2}, 10 \mathrm{mM}$ HEPES, $2.5 \mathrm{~g} / \mathrm{l}$ taurine, $0.18 \mathrm{~g} / \mathrm{l}$ pyruvic acid, and $0.75 \mathrm{~g} / \mathrm{l}$ ribose $(\mathrm{pH}=7.2$ ). After removing the blood the perfusate was switched to nominally $\mathrm{Ca}^{2+}$-free MEM for 10 minutes. Dispersion of cells was achieved by application of $0.5 \mathrm{~g} / \mathrm{l}$ collagenase (Sigma type I) in the presence of $75 \mu \mathrm{M}$ $\mathrm{CaCl}_{2}$ for 40 minutes. During this isolation procedure solutions were gassed with oxygen and the temperature was maintained at $37^{\circ} \mathrm{C}$. Finally, the left ventricular wall was minced and gently agitated. Cardiomyocytes, freshly released from the tissue, were stored at room temperature before use. At least $60 \%$ of the cells were rod-shaped and showed clear striation when the external $\mathrm{Ca}^{2+}$ was restored.

New Zealand white rabbits, weighting 2.3-2.9 kg were also used for cardiomyocyte isolation. A modified Tyrode solution containing (in $\mathrm{mM}$ ): $\mathrm{NaCl} 130$, HEPES 23, taurin 20, creatine 5, $\mathrm{MgCl}_{2}$ 5, Na-pyruvate 5, $\mathrm{KCl} 4.5, \mathrm{NaHPO}_{4}$ 1, glucose 21 was applied. The $\mathrm{pH}$ was adjusted with $\mathrm{NaOH}$ to 7.3. In the first section of the isolation additional $2 \mathrm{mM}$ $\mathrm{CaCl}_{2}$ was applied to wash out the blood then the perfusion was continued using $\mathrm{Ca}^{2+}$ free solution for $5 \mathrm{~min}$. Finally collagenase, protease and $100 \mu \mathrm{M} \mathrm{CaCl}_{2}$ was applied.

\subsection{Recording of APs in multicellular cardiac preparations}

Adult male Sprague-Dawley rats (weighing 150-200g), adult mongrel dogs (weighing 10-20 kg), and New Zealand rabbits (weighting 2.3-2.9 kg) of either sex were anticoagulated with sodium-heparin and anaesthesized with $30 \mathrm{mg} / \mathrm{kg}$ thiopental. The hearts were rapidly removed through right lateral thoracotomy and immediately rinsed in ice-cold Krebs-Henseleit solution or in ice-cold Tyrode solution (containing in $\mathrm{mM}: \mathrm{NaCl}$ 144, $\mathrm{NaH}_{2} \mathrm{PO}_{4} 0.33, \mathrm{KCl} 4, \mathrm{MgCl}_{2}$ 1, glucose 5.5, HEPES 5, $\mathrm{CaCl}_{2} 2$; the $\mathrm{pH}$ of this solution was set to 7.4 with $\mathrm{NaOH}$ ) for $30 \mathrm{sec}$ depending on the type of experiment. APs were recorded from papillary muscle preparations excised from the right ventricular wall of canine, rat, rabbit and human hearts, as well as from left atrial trabeculae of canine and rat hearts, at $37{ }^{\circ} \mathrm{C}$. After excision, the preparations were immediately mounted in the tissue chamber, having a volume of $40 \mathrm{ml}$, and perfused with Krebs-Henseleit or Tyrode solution. All preparations were continuously stimulated with an electrostimulator (Hugo Sachs Elektronik, model 215/II) using constant rectangular voltage pulses (1 Hz, $1 \mathrm{~ms}$ ) delivered through a pair of bipolar platinum electrodes. APs were recorded using the 
conventional microelectrode technique. Sharp microelectrodes, having a tip resistance of 10-20 $\mathrm{M} \Omega$ when filled with $3 \mathrm{M} \mathrm{KCl}$, were connected to an amplifier (Biologic Amplifier, model VF 102). The voltage outputs from the amplifier were displayed on a dual beam memory oscilloscope (Tektronix, model 2230), and sampled at $40 \mathrm{kHz}$ using an analog-todigital converter (Real Time Devices Inc, model ADA 3300). APD measured at 25, 50 and $90 \%$ level of repolarization $\left(\mathrm{APD}_{25,50,90}\right)$ was obtained using Evokewave v1.49 software (Unisip Ltd). The temperature of the superfusate was kept constant at $37{ }^{\circ} \mathrm{C}$. After stabilization of the AP parameters control APs were recorded from the surface region of the tissue samples, then the drug was applied in the superfusate (apamin: 45, AVE0118: $45, \mathrm{BaCl}_{2}: 20$, dofetilide 60 , SEA0400 45 minutes) and the measurements were repeated in the presence of the drug.

To ensure the physiological conditions of our preparations, control $\mathrm{APD}_{90}$ values of 200-220 ms for dogs, 170-200 ms for rabbits, and 50-80 ms for rats at $1 \mathrm{~Hz}$ were accepted as exclusion criteria (i.e. preparations with a control $\mathrm{APD}_{90}$ out of these ranges were discarded). Furthermore, AP amplitude had to be higher than $100 \mathrm{mV}$ in all species. Attempts were made to maintain the same impalement during the whole experiment. When impalement was dislodged, adjustment of the electrode was attempted. If the duration of the AP of the re-established impalement deviated more than $5 \%$ from the previous measurement, the experiment was discarded.

\subsection{Determination of ionic currents in single mammalian ventricular cells}

A drop of the cell suspension was placed into a lucid chamber mounted on the stage of an inverted microscope (Olympus, model IX71), and at least 10 minutes was allowed for cardiomyocytes to adhere before starting the superfusion. Micropipettes were fabricated from borosilicate glass capillaries (Clark Electromedical Instruments) using a microprocessor-controlled horizontal puller (P-97, Sutter Instruments). These electrodes had a resistance of 1.5-2.5 $\mathrm{M} \Omega$ when filled with the given pipette solution. Membrane currents were recorded with an Axopatch 1-D amplifier (Axon Instruments) using the whole-cell or the perforated patch configuration of the patch clamp technique. Gigaseals were established with gentle suction and the cell membrane beneath the tip was disrupted with further suction or by application of short electrical pulses. The series resistance was compensated for $80 \%$. Membrane currents were digitized using an analog-to-digital 
converter (Digidata 1440A), under software control (pClamp 10.0). Membrane currents were recorded from each cell before and after application of the given drug.

\subsubsection{Apamin sensitive current measured by the whole cell patch clamp technique}

The apamin sensitive current was examined in $\mathrm{Na}^{+}$and $\mathrm{Ca}^{2+}$ free Tyrode solution, containing (in $\mathrm{mM}$ ): $\mathrm{N}$-methyl-glucamine $140, \mathrm{KCl} 4, \mathrm{MgCl}_{2} 1$, glucose 5, and HEPES 10 $(\mathrm{pH}=7.4$ with $\mathrm{HCl})$. The internal solution applied during this procedure contained (in $\mathrm{mM}$ ): $\mathrm{K}^{+}$-gluconate 144, $\mathrm{MgCl}_{2}$ 1.15, BAPTA 5, HEPES $10(\mathrm{pH}=7.2)$. Free $\mathrm{Ca}^{2+}$ in the pipette solution was set to $900 \mathrm{nM}$ using an appropriate mixture of $\mathrm{CaCl}_{2}$ and BAPTA, calculated with WinMaxC software [17].

\subsubsection{Apamin-sensitive current measured by perforated patch clamp technique}

In order to prevent major changes in the intracellular milieu of the cells, the apamin sensitive current was also investigated using the perforated patch clamp technique. The pipette solution contained (in $\mathrm{mM}$ ): $\mathrm{K}$-glutamate 120, $\mathrm{KCl} 25, \mathrm{MgCl}_{2} 1$, HEPES 10, EGTA 5, pH 7.4 with $\mathrm{KOH}$. The pipette solution was supplemented with $200 \mu \mathrm{g} / \mathrm{ml}$ amphotericin $\mathrm{B}$ in order to develop a reasonably good electrical access to the cell interior. When amphotericin B penetrated the cell membrane, the access resistance was 15-20 M $\Omega$. The external solution contained (in $\mathrm{mM}$ ): $\mathrm{NaCl} 138, \mathrm{KCl} 4, \mathrm{MgCl}_{2} 1, \mathrm{CaCl}_{2}$ 1.8, $\mathrm{NaHPO}_{4} 0.33$, glucose 10, HEPES 10, pH 7.4 with $\mathrm{NaOH}$. These cells were also loaded with a $\mathrm{Ca}^{2+}-$ sensitive fluorescent dye, Fluo 4AM $(5 \mu \mathrm{M})$, and CaTs were simultaneously recorded.

\subsection{3. $\mathrm{Ca}^{2+}$ dependency of $I_{K 1}$ measured by whole cell patch clamp method}

These experiments were carried out in normal Tyrode solution, while the pipette solution contained (in mM): K-aspartate 100, $\mathrm{KCl} 40, \mathrm{~K}_{2} \mathrm{ATP} 5, \mathrm{MgCl}_{2}$ 3.2, HEPES 10. Depending on the experimental procedure the concentration of EGTA and $\mathrm{CaCl}_{2}$ were adjusted to set the final $\left[\mathrm{Ca}^{2+}\right]_{\mathrm{i}}$ to $160 \mathrm{nM}$ or $900 \mathrm{nM}$ or when unbuffered internal solution was applied, both were omitted. The $\mathrm{pH}$ of the solution was adjusted to 7.2 with $\mathrm{KOH}$.

\subsubsection{Determination of the NCX current using the whole cell patch clamp technique}

To evaluate the NCX current, K-free bath solution was applied containing (in $\mathrm{mM}$ ): $\mathrm{NaCl} 135, \mathrm{CsCl} 10, \mathrm{CaCl}_{2} 1, \mathrm{MgCl}_{2}$ 1, $\mathrm{BaCl}_{2}$ 0.2, $\mathrm{NaHPO}_{4}$ 0.33, TEACl 10, HEPES 10, glucose $10, \mathrm{pH}$ was adjusted to 7.4 with $\mathrm{NaOH}$. This solution was supplemented by $20 \mu \mathrm{M}$ oubain to inhibit NKE, $1 \mu \mathrm{M}$ nisoldipine to block $\mathrm{I}_{\mathrm{CaL}}$, and $50 \mu \mathrm{M}$ lidocaine to suppress $\mathrm{I}_{\mathrm{Na}}$. The pipette solution contained (in $\mathrm{mM}$ ): $\mathrm{CsOH}$ 140, aspartic acid 75, TEACl 20, 
MgATP 5, HEPES 10, $\mathrm{NaCl} 20$, EGTA 20, $\mathrm{CaCl}_{2}$ 10, the $\mathrm{pH}$ was adjusted to 7.2. The $\left[\mathrm{Ca}^{2+}\right]$ in the pipette was $160 \mathrm{nM}$ as calculated by the WinMaxC software [17]).

\subsection{Recording of CaTs in field-stimulated canine and rat ventricular tissues}

Canine and rat right ventricular tissue samples were loaded with $25 \mu \mathrm{M}$ Fluo 4-AM (Molecular Probes Inc.) for 50 minutes at room temperature. The samples were mounted in a low volume Quick Change imaging chamber (RC47FSLP, Warner Instruments) and paced initially at $1 \mathrm{~Hz}$. Fluorescence measurements were performed using an Olympus IX 71 type inverted microscope. Optical signals were recorded by a photon counting PMT module (Hamamatsu, H7828) sampled at $1 \mathrm{kHz}$. The dye was excited at $480 \mathrm{~nm}$, the emission was detected at $535 \mathrm{~nm}$. Measurements were governed by using Isosys software (Experimetria Ltd, Hungary). Frequency-dependent changes in the CaTs were monitored after establishing steady-state conditions at each studied frequency $(0.3,1$, and $3 \mathrm{~Hz})$.

\subsection{Molecular biological techniques}

\subsubsection{Protein isolation and Western blot analysis}

Whole cell tissue lysates were purified from ventricular myocardial tissues of adult hearts (Sprague-Dawley rats, $n=6$, and mongrel dogs, $n=6$ ) and also from canine and rat isolated ventricular myocytes. Briefly, the tissue samples were cut into small pieces in Lysis buffer (containing: $50 \mathrm{mM}$ Tris-HCl, 1\% nonidet P-40, 0.5\% deoxycholate, $150 \mathrm{mM}$ $\mathrm{NaCl}, 10 \mathrm{~g} / \mathrm{l} \mathrm{PMSF}, 5 \mu \mathrm{M}$ leupeptin, $5 \mu \mathrm{M}$ aprotinin, and $5 \mu \mathrm{g} / \mathrm{l} \mathrm{Na}$-vanadate, and Protease inhibitor cocktail (Sigma), homogenized with polytron and centrifuged (10000g, $15 \mathrm{~min}$ ) at $4^{\circ} \mathrm{C}$. Supernatants were collected and protein concentration was measured by Lowry's method using BSA for standard. SDS-polyacrylamide gel electrophoresis was performed in $10 \%$ acrylamide/bis-acrylamide gels. Fractionated proteins were transferred to polyvinylidene difluoride (Immobilon ${ }^{\mathrm{TM}}-\mathrm{P}$ membrane, Millipore) in transfer buffer (containing: $25 \mathrm{mM}$ Tris-HCl, $150 \mathrm{mM}$ glycine, 20\% methanol, $\mathrm{pH}=8.3$ ). To avoid nonspecific binding, blots were blocked using TBST with 10\% non-fat milk (BioRad) and target antigens were labeled overnight with primary antibodies, rabbit polyclonal anti-SK2 (Anti- $\mathrm{K}_{\mathrm{Ca}} 2.2$, Alomone) or murine monoclonal $\alpha$-sarcomeric actin (DAKO) at $4^{\circ} \mathrm{C}$. Binding of the primary antibody was detected with horse radish peroxidase conjugated anti-rabbit or anti-mouse secondary antibodies (DAKO), respectively, and visualized by 
enhanced chemoluminescence assay (ECL Plus kit, Amersham Pharmacia Biotech). Optical densities of protein bands on X-ray films were analyzed by using Image $\mathbf{J}$ and Microsoft Excel programs.

\subsubsection{Immunohistochemistry and confocal microscopy}

Isolated canine and rat ventricular myocytes were fixed by acetone. Before staining the samples were rehydrated in $\mathrm{Ca}^{2+}$-free phosphate buffered saline (PBS) and blocked for 120 min at room temperature with PBST (PBS with $0.01 \%$ Tween) containing $1 \%$ bovine serum albumin. Indirect immunofluorescence staining was performed using rabbit polyclonal anti-SK2 (Anti- $\mathrm{K}_{\mathrm{Ca}} 2.2$, Alomone) primary antibody in 1:50 dilution and a fluorescent secondary antibody, Alexa Fluor 448 conjugated goat anti-rabbit IgG (Molecular Probes Inc) in 1:1000 dilution. The $60 \mathrm{~min}$ period of incubation with the primary antibody at room temperature was followed by further $60 \mathrm{~min}$ incubation with the secondary antibody. Between and after the incubation periods samples were washed thoroughly with PBST. The control samples were only incubated with secondary antibody. For microscopic examination cells were mounted in Aqua Poly/Mount (Polysciences Inc). Fluorescent images of the immunostained samples were captured by an Olympus FV1000 confocal laser scanning microscope used with standard parameter settings.

\subsection{Drugs}

All chemicals were purchased from Sigma except otherwise indicated. Apamin was dissolved in $50 \mathrm{mM}$ acetic acid yielding a stock solution of $100 \mu \mathrm{M}$ concentration, which was stored at $-20{ }^{\circ} \mathrm{C}$. Both AVE0118 (gift from Aventis Pharma) and dofetilide (gift from Gedeon Richter Ltd) were dissolved in dimethyl sulfoxide, resulting drug concentrations of $5 \mathrm{mM}$ and $1 \mathrm{mM}$, respectively. $\mathrm{BaCl}_{2}$ was dissolved in water, in stock solutions of 100 mM. SEA0400 (2-(4-((2,5-difluorophenyl)methoxy)phenoxy)-5-ethoxy-aniline) has been synthetized in the Department of Pharmaceutical Chemistry, University of Szeged, Szeged, Hungary, and dissolved in dimethyl sulfoxide. The stock solution was $10 \mathrm{mM}$. The stock solutions were stored at $4{ }^{\circ} \mathrm{C}$. All solutions used were made freshly prior to the experiment.

\subsection{Statistics}

Data are expressed as mean values \pm SEM. Student t-test for paired data was used to compare results. Results were considered significant when the p value was less than 0.05. 


\section{RESULTS}

\subsection{Functional analysis of the cardiac SK channels}

\subsubsection{Expression of $\mathrm{SK} 2$ channel protein in canine and rat ventricular myocardium}

As indicated by the representative Western blot samples, shown in Fig. 3.A/a, SK2 channel protein was abundantly expressed in both canine and rat ventricular tissues. Results of the semiquantitative assay revealed approximately similar levels of SK2 protein expression in both species. To exclude the contribution of SK2 proteins derived from vessels, Western-blot analysis was also performed in isolated rat and canine ventricular cells. SK2 protein was clearly detectable at $60 \mathrm{kDa}$ in both species, with similar protein levels (Fig. 3.A/b).

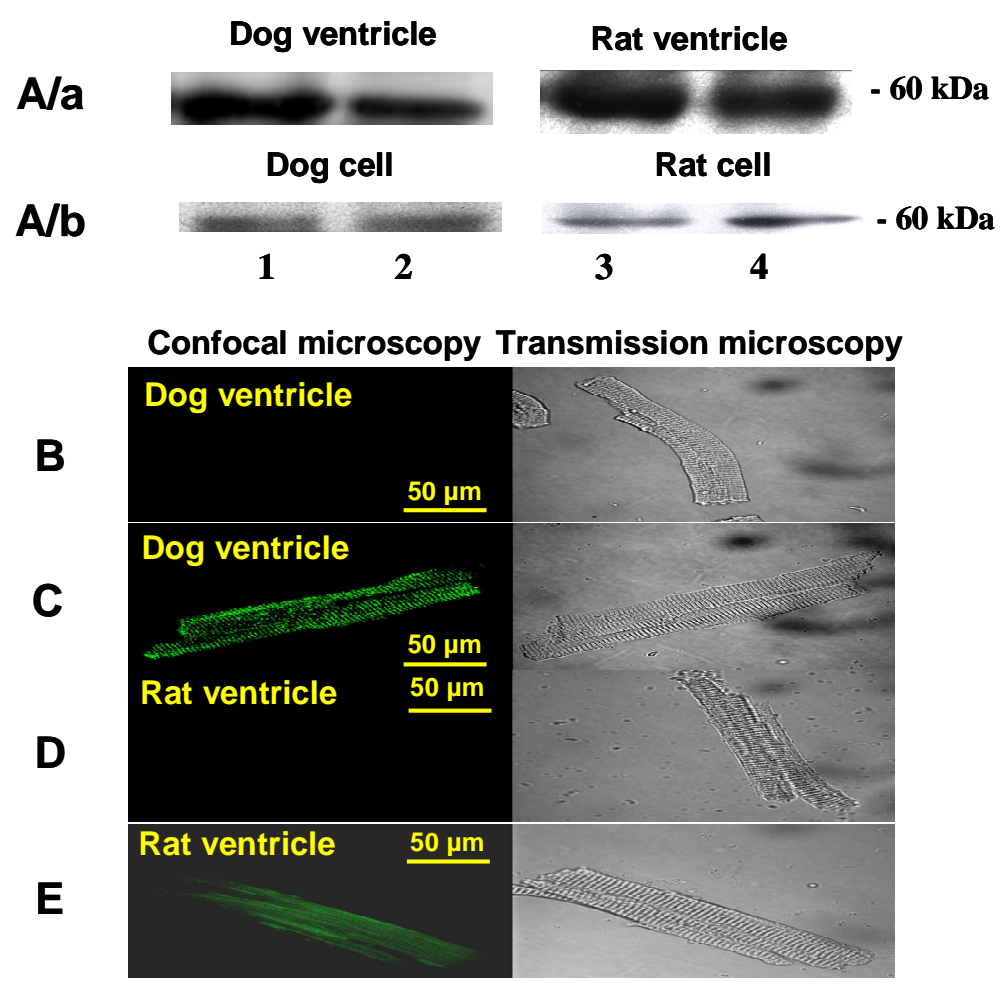

Fig.3. Expression of SK2 channel protein in canine and rat ventricular myocardium. A: Representative immunoblots of SK2 protein obtained in canine $(1,2)$ and rat $(3,4)$ left ventricular myocardium obtained from multicellular tissues $(A / a)$ and from isolated myocytes $(A / b)$. Proteins were purified from 6 canine and 6 rat hearts and separated using 10\% SDS-PAGE. Protein expression was detected at a molecular weight of $60 \mathrm{kDa}$. B-E: Confocal (left columns) and transmission microscopic (right columns) images captured from surface focus plane of isolated canine $(\boldsymbol{B}, \boldsymbol{C})$ and rat $(\boldsymbol{D}, \boldsymbol{E})$ ventricular myocytes. Panels $\boldsymbol{C}$ and $\boldsymbol{E}$ show immunostained cells, while in $\boldsymbol{B}$ and $\boldsymbol{D}$ the respective negative controls, stained only with Alexafluor 488-labeled secondary antibody, are depicted. 
For further confirmation, the distribution of SK2 channel protein was detected directly in isolated myocytes. Confocal microscopic images of immunostained cardiomyocytes also revealed comparable surface distribution of SK2 channel protein in both canine (Fig. 3.C) and rat (Fig. 3.E) ventricular cells. Respective negative controls are depicted in panels B and D.

\subsubsection{Measurements of intracellular CaTs}

Since both the investigation of SK-channels and $\mathrm{I}_{\mathrm{K} 1}$ requires the presence of CaTs in the cardiac preparations, prior to the electrophysiological experiments, thus we also demonstrated the presence of normal CaTs in multicellular papillary muscles (Fig. 4.). The shape of the recorded CaTs was close to those obtained from single isolated cardiomyocytes. The effects of $\left[\mathrm{Ca}^{2+}\right]_{0}$ modulation on CaTs (systolic and diastolic levels) were also evaluated. Elevation of $\left[\mathrm{Ca}^{2+}\right]_{\mathrm{o}}$ to $4 \mathrm{mM}$ resulted in $35 \pm 11 \%$ increase in the amplitude of the CaT (Fig. 4.A and B). In contrast, the elevation in diastolic value was below the experimental variance (Fig. 4.A-B). These results clearly demonstrate that the multicellular AP measurement technique is suitable for investigation of $\mathrm{Ca}^{2+}$ induced alterations in the AP.
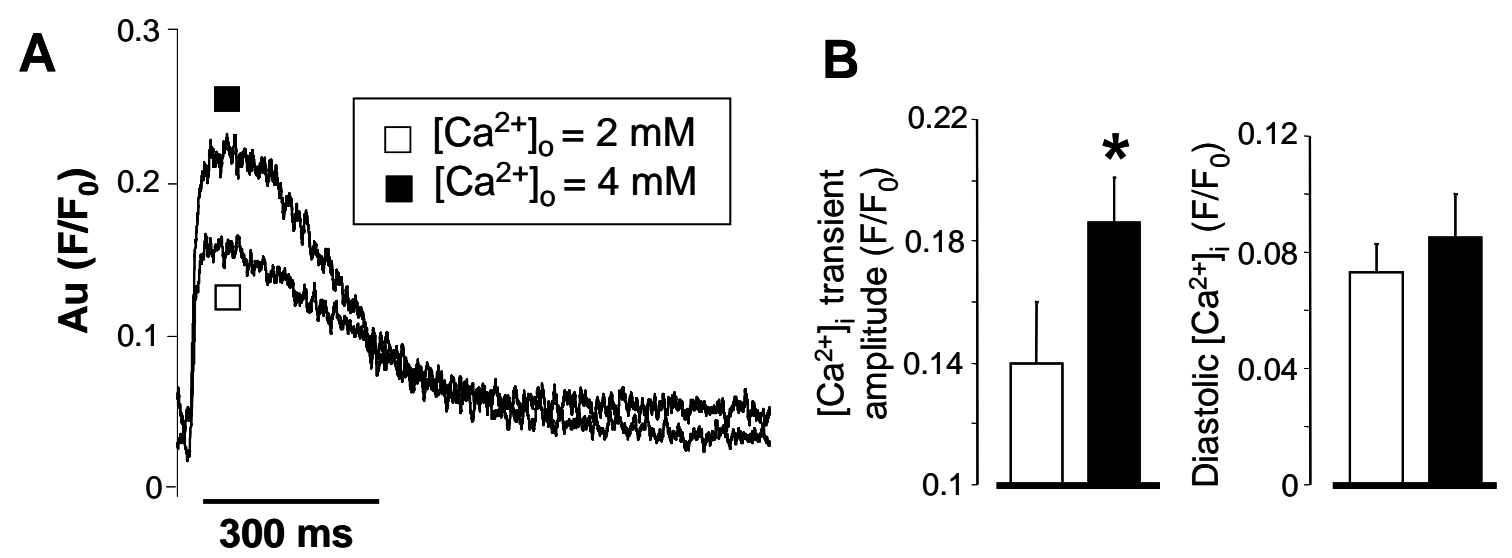

Fig.4. A Effect of $\left[\mathrm{Ca}^{2+}\right]_{o}$ on CaTs in canine ventricular muscles. CaTs were recorded in the presence of $2 \mathrm{mM}$ and $4 \mathrm{mM}\left[\mathrm{Ca}^{2+}\right]_{o}$ indicated by the open and filled symbols, respectively. Amplitude of $\left[\mathrm{Ca}^{2+}\right]_{i}$ transients and diastolic $\left[\mathrm{Ca}^{2+}\right]_{i}$ levels determined using the fluorescent $\left[\mathrm{Ca}^{2+}\right]_{i}$ indicator dye Fluo 4. B Columns and bars represent mean \pm SEM values obtained in 6 preparations. Asterisks denote significant $(p<0.05)$ differences between results obtained in the presence of 2 and $4 \mathrm{mM}\left[\mathrm{Ca}^{2+}\right]_{\text {o. }}$ 


\subsubsection{Effect of apamin on APs recorded from canine, rat, and human multicellular cardiac preparations}

The effect of $100 \mathrm{nM}$ apamin on the kinetics of AP was tested using the conventional microelectrode technique in right ventricular papillary muscles and left atrial trabeculae excised from canine, rat, and undiseased human hearts. All preparations were paced at a constant frequency of $1 \mathrm{~Hz}$ in Krebs-Henseleit solution. Representative pairs of APs, recorded from the same preparations before and after $45 \mathrm{~min}$ exposure to $100 \mathrm{nM}$ apamin, are depicted in panels A-E of Fig. 5, while the summarized results are presented in Fig. 5.F. As shown in Fig. 5, none of the preparations responded to apamin exposure with alterations in APD. These results suggest that the SK channels - in spite of their abundant expression - fail to mediate significant amount of ion current under physiological conditions (at least, when studied in multicellular atrial and ventricular preparations of the various species).
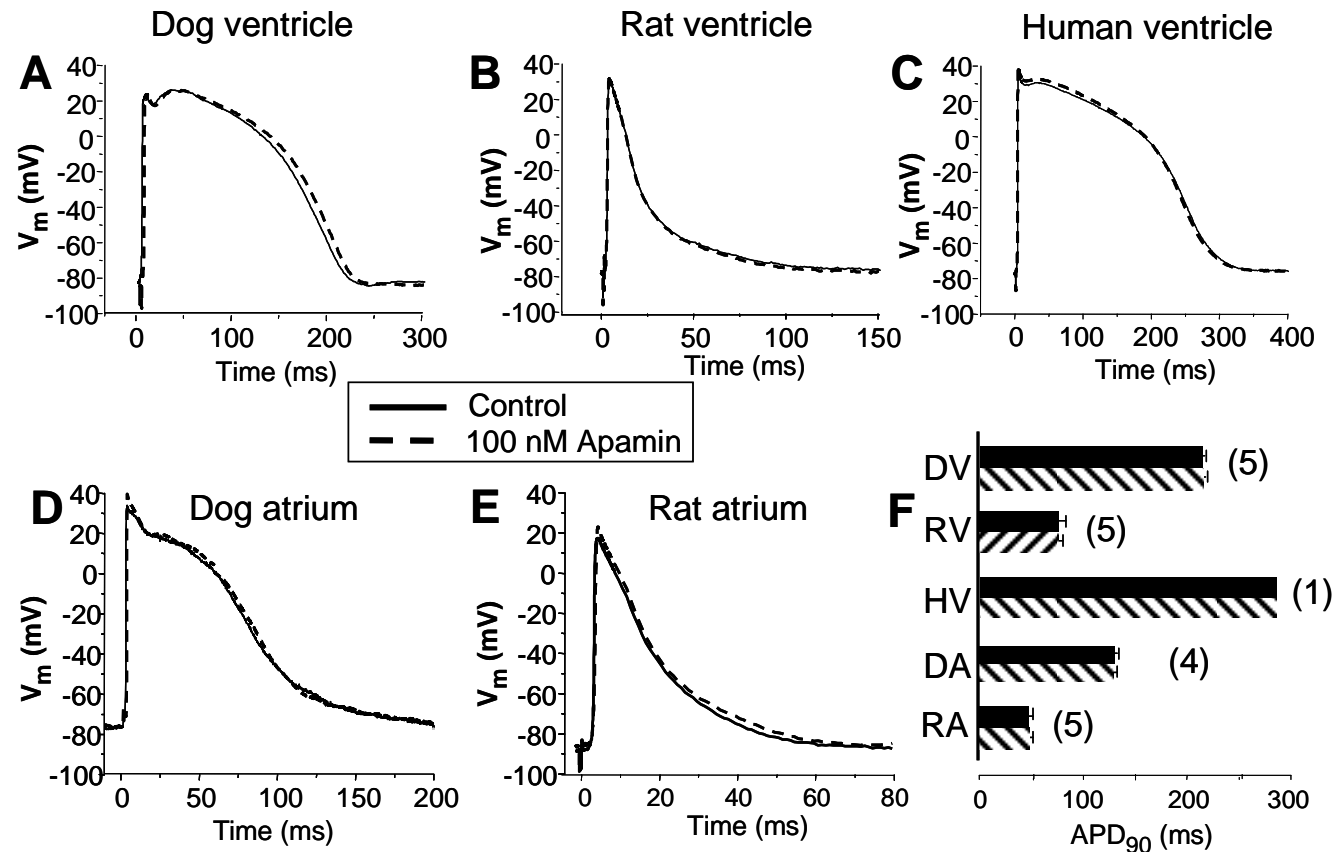

Fig.5. Effect of $100 \mathrm{nM}$ apamin on AP configuration in multicellular cardiac preparations recorded at a stimulation frequency of $1 \mathrm{~Hz}$. A-E: Representative pairs of APs, recorded from the same preparations before and after 45 min exposure to $100 \mathrm{nM}$ apamin. The preparations exposed to apamin were canine right ventricular papillary muscles $(D V)$, rat right ventricular papillary muscles $(R V)$, human right ventricular papillary muscle $(H V)$, canine left atrial trabeculae (DA), and rat left atrial trabeculae (RA). The average results obtained for $A P D_{90}$ are shown in panel $\boldsymbol{F}$. Columns and bars represent mean data $\pm S E M$, numbers in parentheses denote the number of preparations tested.

Since activation of the SK channels is tightly dependent on elevation of the cytosolic free $\mathrm{Ca}^{2+}$, the effect of $100 \mathrm{nM}$ apamin on the AP configuration was also evaluated in canine and rat right ventricular papillary muscles paced with varying frequencies. 
Representative AP pairs recorded from the same preparation before and after exposure to apamin and presented in Fig. 6.A-C., indicate that the APD was not modulated by apamin at any pacing frequency.

Average canine $\mathrm{APD}_{90}$ values were $215 \pm 5.0$ versus $219 \pm 4.0 \mathrm{~ms}$ at $0.3 \mathrm{~Hz}, 207 \pm 3.0$ versus $209.5 \pm 3.5 \mathrm{~ms}$ at $1 \mathrm{~Hz}$, and $188.0 \pm 3.0$ versus $188.5 \pm 3.5 \mathrm{~ms}$ at $3 \mathrm{~Hz}$, respectively, before and after apamin $(n=5)$. The respective values in rat preparations were $83.8 \pm 7.1$ versus $83.2 \pm 8.1 \mathrm{~ms}$ at $0.3 \mathrm{~Hz}, 73.0 \pm 3.5$ versus $72.6 \pm 2.5 \mathrm{~ms}$ at $1 \mathrm{~Hz}$, and $71.2 \pm 2.9$ versus $72.6 \pm 3.4 \mathrm{~ms}$ at $3 \mathrm{~Hz}(\mathrm{n}=5)$.

Representative CaTs, recorded from right ventricular tissues of dogs and rats, paced at $0.3,1$, and $3 \mathrm{~Hz}$ are presented in the right columns of Fig.6.D-F. According to these graphs the highest $\left[\mathrm{Ca}^{2+}\right]_{\mathrm{i}}$ values were observed at $3 \mathrm{~Hz}$ in canine myocytes, while the lowest at $0.3 \mathrm{~Hz}$ in the case of rat ventricular tissues, following the predictions of the positive and negative staircase phenomena, respectively, known to be characteristic of canine and rat ventricular myocardium. In spite of the elevated $\left[\mathrm{Ca}^{2+}\right]_{i}$ values seen at these frequencies no effect of apamin on AP duration was observed.

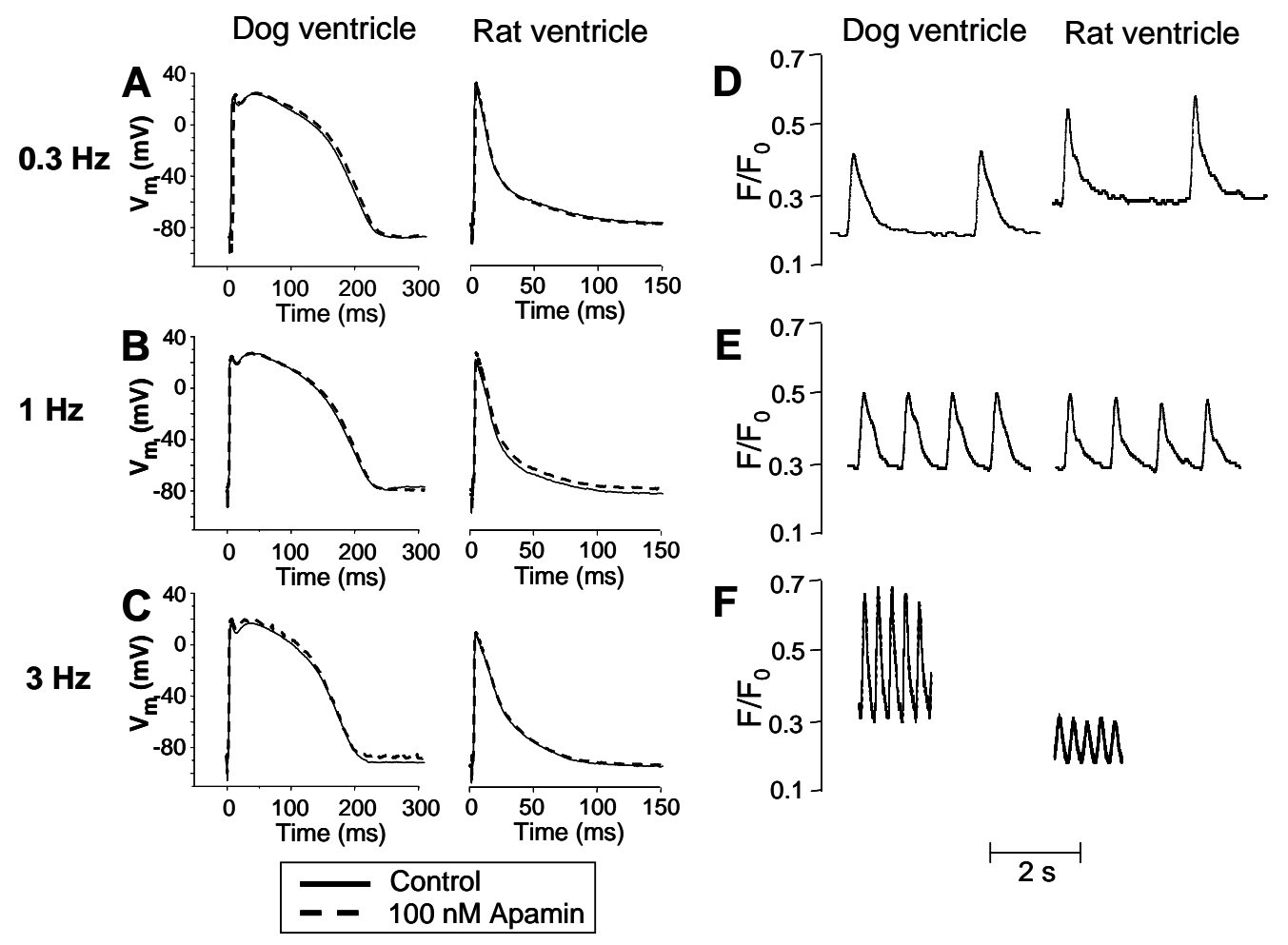

Fig.6. A-C: Effect of $100 \mathrm{nM}$ apamin on AP configuration in canine and rat ventricular muscles recorded at pacing frequencies of $0.3,1$ and $3 \mathrm{~Hz}$. Representative pairs of APs taken from the same preparations before after the application of $100 \mathrm{nM}$ apamin are presented. D-F: Representative traces of intracellular CaTs recorded from canine and rat ventricular tissues at the identical frequencies $(0.3,1$ and $3 \mathrm{~Hz})$. 
In order to exclude the possibility that a strong repolarization reserve may fully compensate for any apamin-induced APD lengthening, prior to the application of apamin we also blocked the major repolarizing currents. These interventions are known to augment changes in APD induced by the blockade of other outward currents. In canine papillary muscles $\mathrm{I}_{\mathrm{Kr}}$ was blocked by $300 \mathrm{nM}$ dofetilide, in rat preparations $5 \mu \mathrm{M}$ AVE0118 was used to inhibit the $\mathrm{I}_{\text {to }}$ plus $\mathrm{I}_{\mathrm{Kur}}$. While a substantial attenuation of the repolarization reserve was obtained in the presence of these drugs (as confirmed by a significant lengthening of $\mathrm{APD}_{90}$ in both species, shown in Fig.7.A-B, apamin exposure failed to alter APD even under these circumstances (i.e. when the repolarization reserve was greatly compromised). In canine papillary muscles $\mathrm{APD}_{90}$ was increased by $300 \mathrm{nM}$ dofetilide from $211 \pm 3.0$ to $245 \pm 5.7 \mathrm{~ms}(\mathrm{p}<0.05, \mathrm{n}=5)$, and $247 \pm 6.0 \mathrm{~ms}$ was measured when $100 \mathrm{nM}$ apamin was superfused in the presence of dofetilide. The respective values in the case of rat preparations were: $70.8 \pm 5.2 \mathrm{~ms}$ in control, $148.2 \pm 7.3 \mathrm{~ms}$ in the presence of $5 \mu \mathrm{M}$ AVE0400 ( $\mathrm{p}<0.05, \mathrm{n}=5)$, and $148.4 \pm 7.0 \mathrm{~ms}$ following further exposure to $100 \mathrm{nM}$ apamin.
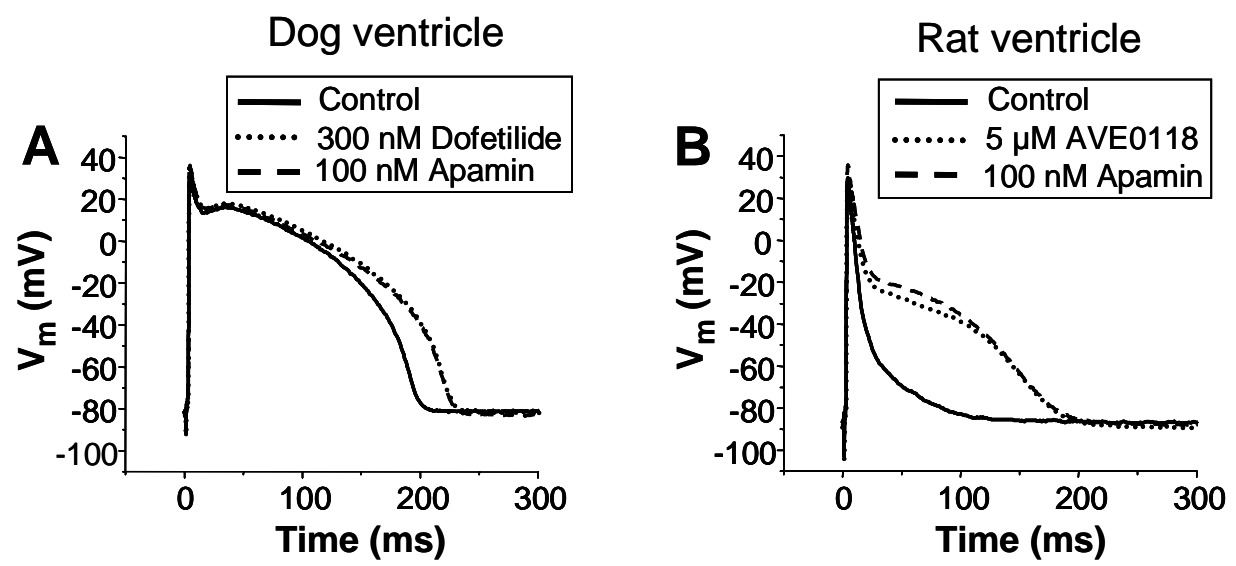

Fig.7. Effect of apamin in preparations with attenuated repolarization reserve due to pretreatment with dofetilide in canine $(\boldsymbol{A})$ and AVE0118 in rat (B) ventricular myocardium at $1 \mathrm{~Hz}$. Apamin (100 $n M)$ was applied in the presence of $300 \mathrm{nM}$ dofetilide and $5 \mu M A V E 0118$, respectively

\subsubsection{Effect of $1 \mu \mathrm{M}$ SEA0400 on ventricular AP and CaT}

NCX current was measured in dog, rabbit and rat myocytes by applying voltage ramps $(100 \mathrm{mV} / \mathrm{s}$ with rate of $0.2 \mathrm{~Hz})$ from a holding potential of $-40 \mathrm{mV}$ to $+60 \mathrm{mV}$ then hyperpolarized to $-100 \mathrm{mV}$. The outward NCX current (reverse mode activity of NCX) was determined at $+40 \mathrm{mV}$ while the inward current (forward mode) at $-80 \mathrm{mV}$. Following the control recordings SEA0400 $(1 \mu \mathrm{M})$ was applied for $5 \mathrm{~min}$. $10 \mathrm{mM} \mathrm{NiCl} 2$ was used to approximate the total NCX current. The inhibitory effect of SEA0400 was characterized by the ratio of the SEA0400-induced NCX current shift and the $\mathrm{Ni}^{2+}$-sensitive current. 
In canine cardiomyocytes, following the application of $1 \mu \mathrm{M}$ SEA0400 the outward current was found to be inhibited by $76.6 \pm 3.4 \%$ while the extent of forward mode block was $52.8 \pm 5.9 \%(n=8)$. Contrary to the significant NCX current inhibition, the $\mathrm{APD}_{90}$ (measured in multicellular preparations) remained unchanged following the administration of $1 \mu \mathrm{M}$ SEA0400 (221 $\pm 7.4 \mathrm{~ms}$ versus $224.6 \pm 4.8 \mathrm{~ms}$, after SEA0400, $\mathrm{n}=5)$.

In rabbit cardiomyocytes $1 \mu \mathrm{M}$ SEA0400 again markedly decreased the NCX current in both directions: the level of inhibition on the outward current was $64.1 \pm 2.3 \%$, and on the inward current was $65.4 \pm 8.8 \%(n=7)$. In rabbit papillary muscles $1 \mu \mathrm{M}$ SEA0400 caused a small, statistically insignificant abbreviation in the $\mathrm{APD}_{90}(181.5 \pm 3.77$ ms versus $175 \pm 8.5$ ms, $n=5)$.

In rat cardiomyocytes $1 \mu \mathrm{M}$ SEA0400 had slightly larger effect on the reverse mode $\operatorname{NCX}(70.5 \pm 10.2 \%)$ than on the forward mode $(59.3 \pm 4.5 \%)(n=5)$. However, the $\mathrm{APD}_{90}$ did not change following SEA0400 administration (63 $\pm 5 \mathrm{~ms}$ versus $68.5 \pm 0.5 \mathrm{~ms} ; \mathrm{n}=3)$.
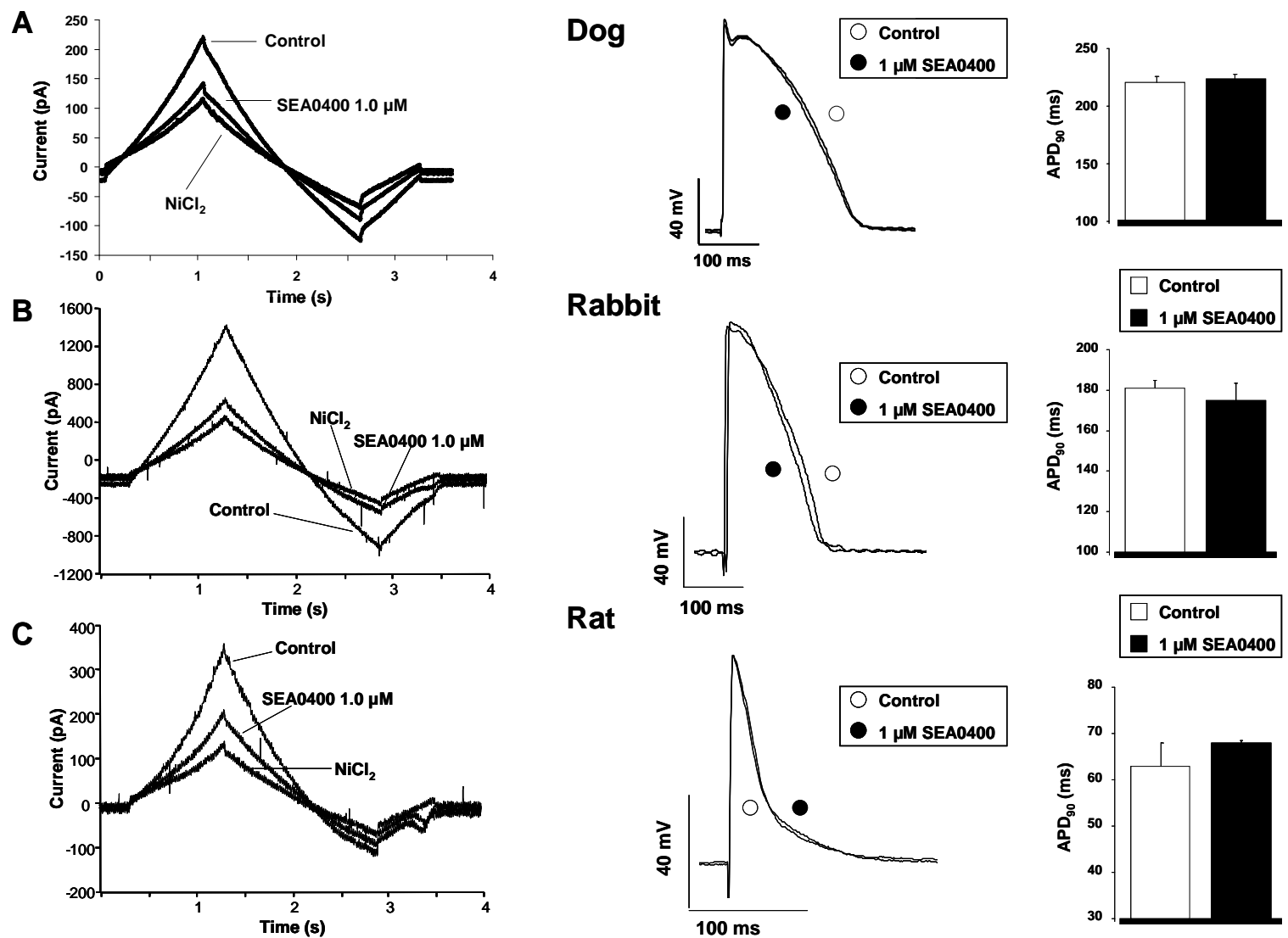

Rat
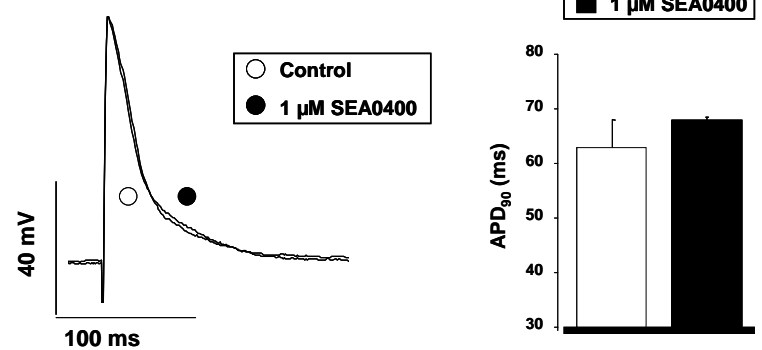

Fig.8. Effect of $1 \mu M$ SEA0400 on the NCX current measured in isolated single cells and on the APs obtained from right ventricular papillary muscles from dog $(\boldsymbol{A})$, rabbit $(\boldsymbol{B})$ and rat $(\boldsymbol{C})$. In all three species, in spite of the marked effects on the NCX current, APs remained unchanged following SEA0400 administration. 


\subsubsection{Effect of apamin on ion currents in single canine and rat ventricular cells}

To detect any effect of apamin on SK current in single cardiomyocytes, we applied both the whole-cell and the perforated patch clamp techniques and measured the apaminsensitive current in isolated canine and rat ventricular myocytes. Under whole cell conditions, the free $\mathrm{Ca}^{2+}$ concentration in the pipette solution was set to $900 \mathrm{nM}$ in order to induce maximal activation of SK channels. This $\left[\mathrm{Ca}^{2+}\right]_{\mathrm{i}}$ is close to the values normally occurring during systole [18]. Test depolarizations, arising from the holding potential of $50 \mathrm{mV}$, were applied to membrane potentials ranging from -120 to $+60 \mathrm{mV}$ for $150 \mathrm{~ms}$.

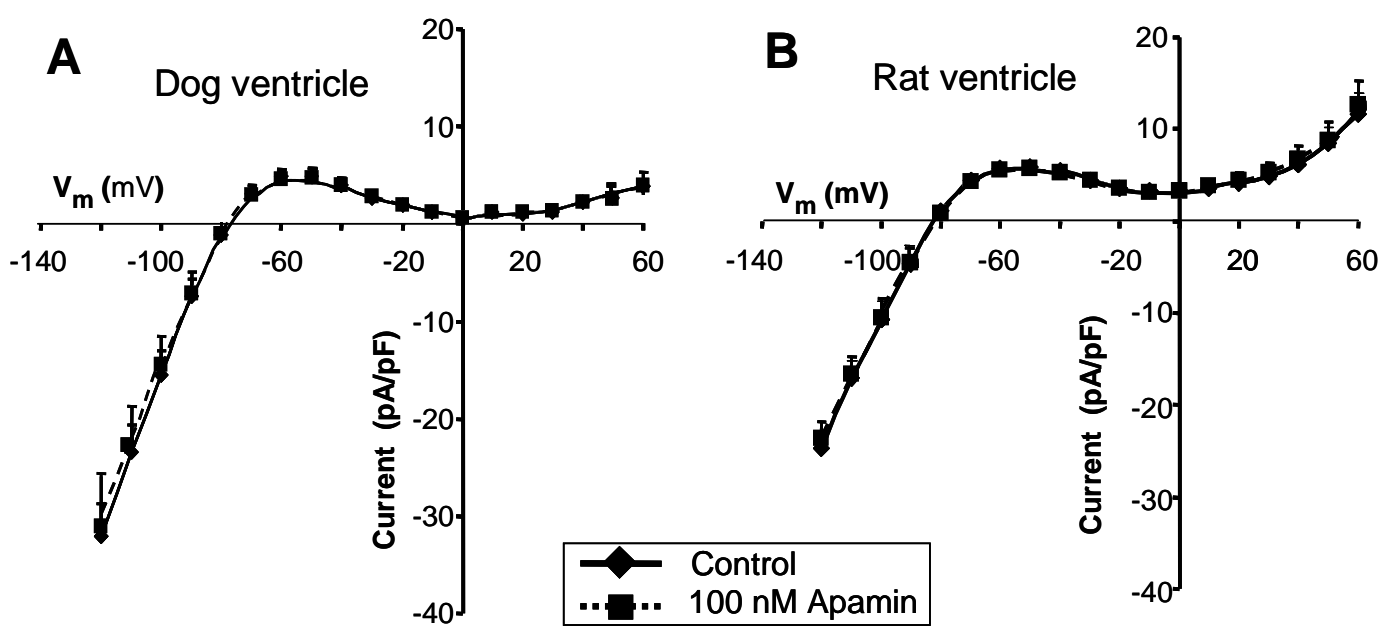

Fig.9. The effect of $100 \mathrm{nM}$ apamin on membrane currents recorded from voltage clamped canine (A) and rat $(\boldsymbol{B})$ ventricular myocytes. Steady-state current-voltage relations were obtained by plotting the end-pulse membrane current as a function of the respective membrane potential $\left(V_{m}\right)$. Measurements were performed before and after the application of $100 \mathrm{nM}$ apamin. Symbols and bars represent mean data $\pm S E M$, the number of myocytes were 7 in both groups. Error bars are missing when smaller than symbol size.

Membrane currents recorded at the end of these pulses and normalized to cell capacitance were plotted against the respective test potential. Since our external and pipette solutions were sodium- and $\mathrm{Ca}^{2+}$-free, and were also poor in chloride, the recorded membrane current was carried exclusively by $\mathrm{K}^{+}$. These "steady-state" current-voltage relations, obtained before and after the exposure to $100 \mathrm{nM}$ apamin, were fully identical in both canine and rat ventricular cells (Fig. 9.A-B, respectively, $n=7$ for each) indicating that apamin failed to activate any ion current in these myocytes throughout the entire voltage range tested. Under perforated patch clamp conditions the cytosol was prevented from dialysis. The cells were loaded with the fluorescent dye fluo 4AM to monitor the $\mathrm{Ca}^{2+}$ release simultaneously to membrane current measurements. 

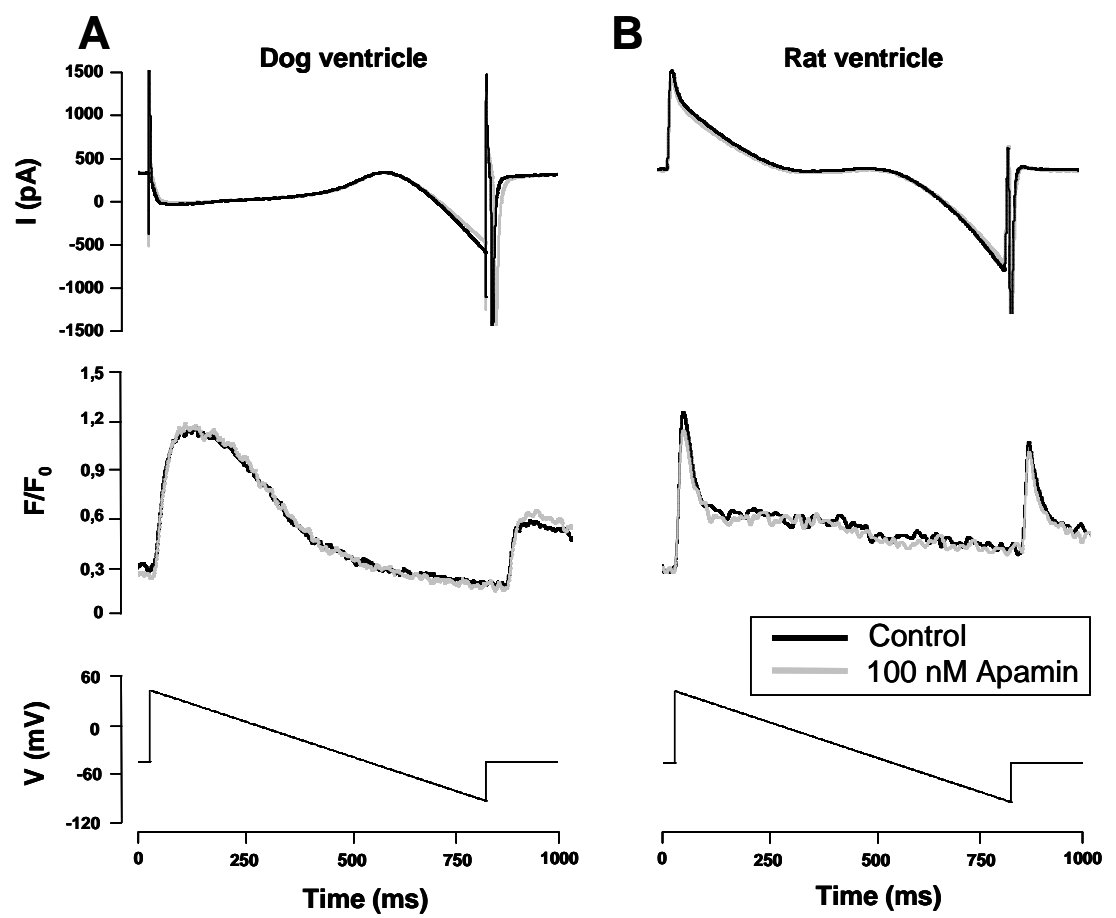

Fig.10. Effect of $100 \mathrm{nM}$ apamin on transmembrane currents recorded from canine and rat $(\boldsymbol{A}$ and $\boldsymbol{B}$ respectively, upper panel) ventricular myocytes under perforated patch clamp conditions. Current was obtained using a voltage ramp arising from a holding potential of $-50 \mathrm{mV}$ to $+40 \mathrm{mV}$, then hyperpolarizing to $-100 \mathrm{mV}$ at a rate of $175 \mathrm{mV} / \mathrm{s}$ (lower panels). The cells were loaded with $5 \mu M$ Fluo 4-AM allowing for simultaneous recording of CaTs (A and $\boldsymbol{B}$, middle panels). The pipette solution contained $5 \mathrm{mM}$ EGTA to indicate any accidental disruption of the patch. The effect of apamin was attempted to investigate as a difference current, however, no effect of apamin could be detected

The membrane was initially depolarized from a holding potential of $-50 \mathrm{mV}$ to +40 $\mathrm{mV}$, then it was hyperpolarized to $-100 \mathrm{mV}$ (at a rate of $175 \mathrm{mV} / \mathrm{s}$ ). Upon depolarization CaTs could be clearly observed indicating normal functional $\mathrm{Ca}^{2+}$ homeostasis in these cells. However, the steady-state membrane current failed again in either species to alter following the administration of $100 \mathrm{nM}$ apamin (Fig. 10.A-B).

\subsection{The effect of increased $\left[\mathrm{Ca}^{2+}\right]_{i}$ on $I_{K 1}$}

\subsubsection{The effect of $\left[\mathrm{Ca}^{2+}\right]_{0}$ on AP characteristics}

APs from canine were determined under normal $(2 \mathrm{mM})\left[\mathrm{Ca}^{2+}\right]_{\mathrm{o}}$ or elevated $(4 \mathrm{mM})$ $\left[\mathrm{Ca}^{2+}\right]_{0}$ conditions (Fig. 11.A). Under normal conditions the kinetics of APs was as expected ( $\mathrm{APD}_{90}$ : $202.38 \pm 3.48 \mathrm{~ms} ; \mathrm{APD}_{50}$ : $154.25 \pm 3.47 \mathrm{~ms} ; \mathrm{APD}_{25}: 118 \pm 3.57 \mathrm{~ms}$ ). Elevated $\left[\mathrm{Ca}^{2+}\right]_{\mathrm{i}}$ caused significant AP shortening (Fig. 11.A and B) without interfering the resting membrane potential $\left(\mathrm{APD}_{90}: 185.2 \pm 8.18 \mathrm{~ms} ; \mathrm{APD}_{50}: 121.8 \pm 1.93 \mathrm{~ms} ; \mathrm{APD}_{25}\right.$ : $76.2 \pm 5.85 \mathrm{~ms})$. Furthermore, in the presence of $4 \mathrm{mM}\left[\mathrm{Ca}^{2+}\right]_{\mathrm{o}}$ the velocity of the terminal repolarization was also increased. 

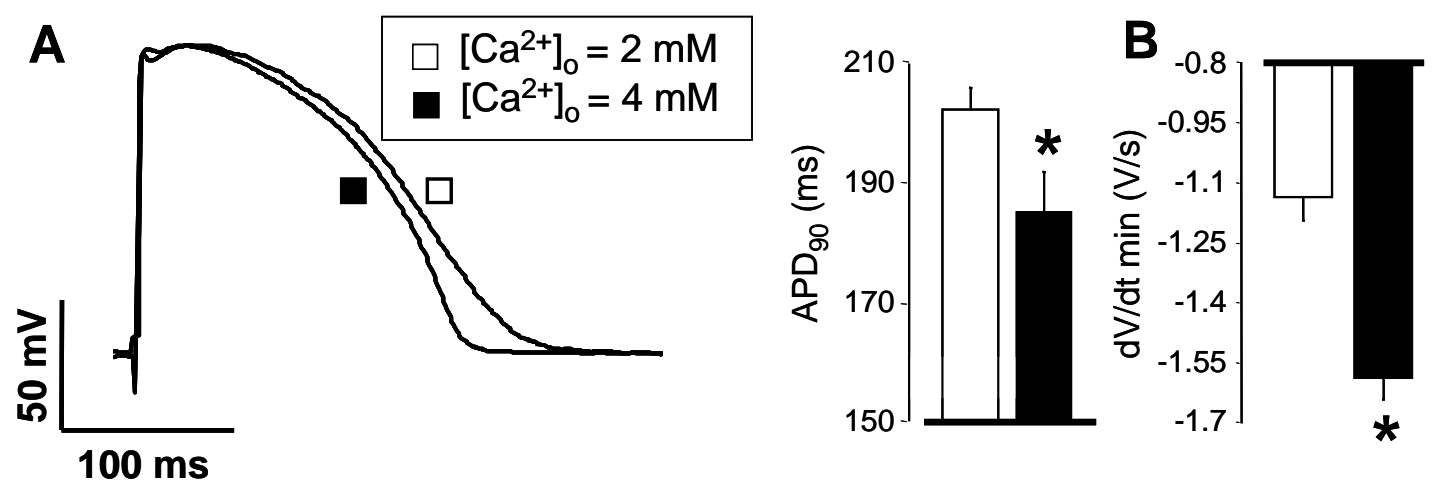

Fig.11. A Effect of $\left[\mathrm{Ca}^{2+}\right]_{o}$ on AP configuration of canine was recorded in the presence of $2 \mathrm{mM}$ and $4 \mathrm{mM}\left[\mathrm{Ca}^{2+}\right]_{o}$ indicated by the open and filled symbols, respectively. AP duration measured at $90 \%$ repolarization $\left(A P D_{90}\right)$.B Maximum rate of terminal repolarization $(d V / d t)$. Columns and bars represent mean \pm SEM values obtained in 6 preparations. Asterisks denote significant $(p<0.05)$ differences between results obtained in the presence of 2 and $4 \mathrm{mM}\left[\mathrm{Ca}^{2+}\right]_{o}$

\subsubsection{The effect of $10 \mu \mathrm{M} \mathrm{BaCl} \mathrm{B}_{2}$ on the $\mathrm{AP}$}

A selective $\mathrm{I}_{\mathrm{K} 1}$ blocker $\left(10 \mu \mathrm{M} \mathrm{BaCl}_{2}\right)$ [4] was used to evaluate the effects of $\left[\mathrm{Ca}^{2+}\right]_{\mathrm{o}}$ modulation on the current. At normal $\left[\mathrm{Ca}^{2+}\right]_{\mathrm{o}}$ and pacing at $1 \mathrm{~Hz} \mathrm{BaCl}_{2}$ lengthened both $\mathrm{APD}_{90} \quad(202.38 \pm 3.48 \mathrm{~ms} \quad$ vs $222.88 \pm 2.8 \mathrm{~ms} ; \quad \Delta 10.84 \pm 0.84 \% ; \mathrm{p}<0.05)$ and $\mathrm{APD}_{50}$ $(154.25 \pm 3.47 \mathrm{~ms}$ vs $162.88 \pm 3.39 \mathrm{~ms})$ however, $\mathrm{APD}_{25}$ was statistically unaffected $(118 \pm 3.57 \mathrm{~ms}$ vs $121.75 \pm 3.39 \mathrm{~ms})$. The resting membrane potential also remained unchanged. $\left[\mathrm{Ca}^{2+}\right]_{\mathrm{i}}$ rise following $\left[\mathrm{Ca}^{2+}\right]_{\mathrm{o}}$ elevation to $4 \mathrm{mM}$ increased significantly the effect of $10 \mu \mathrm{M} \quad \mathrm{BaCl}_{2}$ on $\mathrm{APD}_{90} \quad(185.2 \pm 8.18 \mathrm{~ms} \quad v s \quad 231.20 \pm 13.14 \quad \mathrm{~ms}$; $\Delta=19.6 \pm 1.9 \% ; \mathrm{p}<0.05)$ and $\mathrm{APD}_{50}(121.8 \pm 1.93 \mathrm{~ms} v s 141.8 \pm 3.99 \mathrm{~ms})$ compared to normal settings (Fig. 12.A and C), but did not affect resting membrane potential.

The effect of $\left[\mathrm{Ca}^{2+}\right]_{0}$ elevation on $\mathrm{I}_{\mathrm{K} 1}$ inhibition was also analyzed in paired experiments: following the first application of $10 \mu \mathrm{M} \mathrm{BaCl} 2$ under normal conditions $\mathrm{BaCl}_{2}$ was completely washed out, $\left[\mathrm{Ca}^{2+}\right]_{0}$ was raised up to $4 \mathrm{mM}$ and $\mathrm{BaCl}_{2}$ was reapplied. The effect of selective $\mathrm{I}_{\mathrm{K} 1}$ inhibition on $\mathrm{APD}_{90}$ lengthening was clearly augmented (Fig. 12.B). 


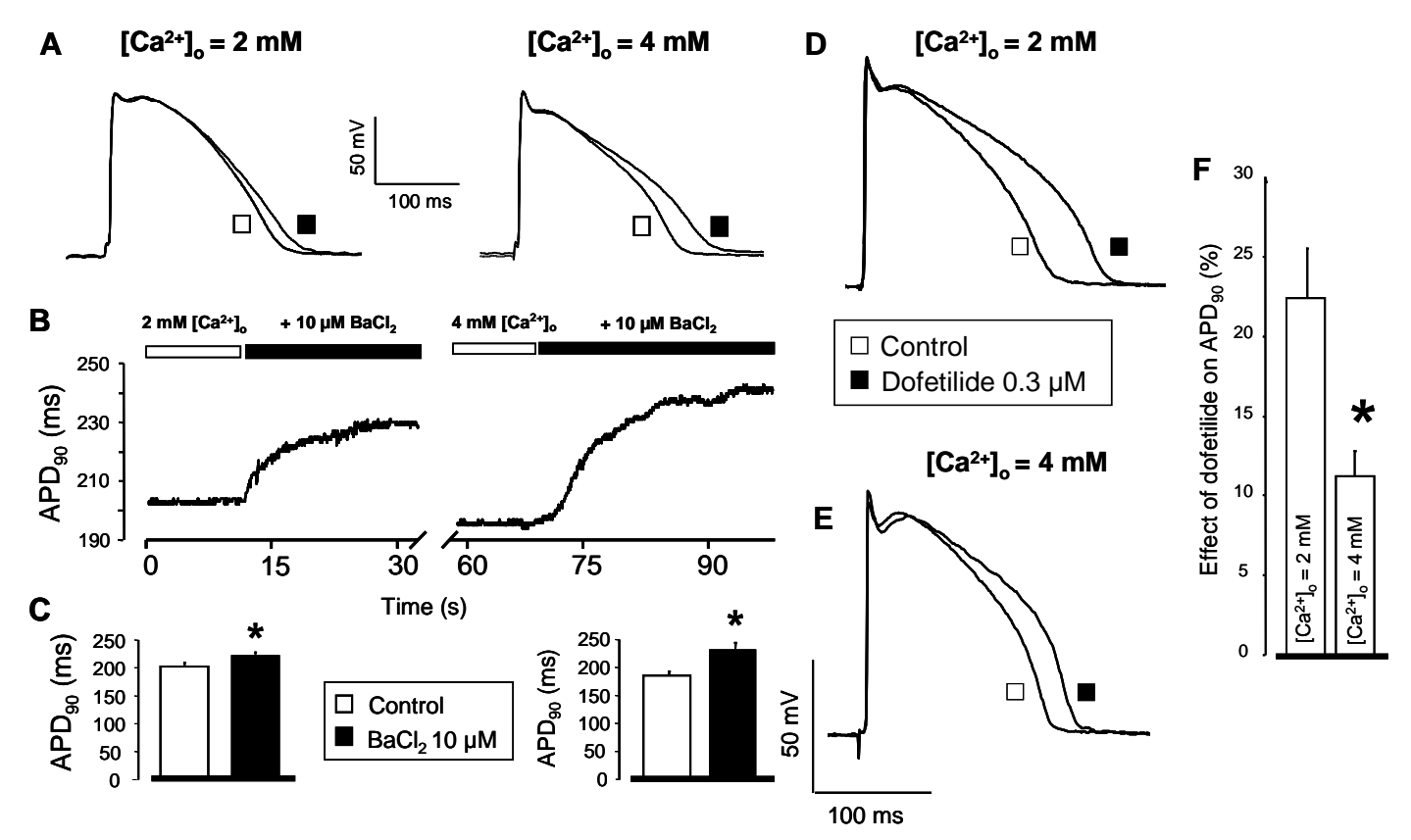

Fig.12. Effect of $10 \mu \mathrm{M} \mathrm{BaCl} l_{2}$ and $0.3 \mu \mathrm{M}$ dofetilide on APD recorded in canine ventricular muscles in the presence of $2 \mathrm{mM}$ and $4 \mathrm{mM}\left[\mathrm{Ca}^{2+}\right]_{o}$. A Representative superimposed pairs of APs recorded before (open symbols) and after (filled symbols) superfusion with $10 \mu \mathrm{MBaCl} \mathrm{B}_{2}$ B Representative records taken from a ventricular muscle: the preparation was first exposed to 10 $\mu \mathrm{M} \mathrm{BaCl} l_{2}$ in the presence of $2 \mathrm{mM}\left[\mathrm{Ca}^{2+}\right]_{o}$, then $\mathrm{BaCl}_{2}$ was washed out, $\left[\mathrm{Ca}^{2+}\right]_{o}$ was elevated to 4 $m M$ and the $\mathrm{BaCl}_{2}$ exposure was repeated. $\mathrm{C}$ Average $A P D_{90}$ values obtained in 6 preparations. Asterisks indicate significant $(p<0.05)$ differences between results of 2 and $4 \mathrm{mM}\left[\mathrm{Ca}^{2+}\right]_{o} . \boldsymbol{D}, \boldsymbol{E}$ Representative superimposed pairs of APs recorded before (open symbols) and after (filled symbols) superfusion with $0.3 \mu M$ dofetilide. $\boldsymbol{F}$ Average $A P D_{90}$ values obtained in 5 preparations. Asterisk indicate significant $(p<0.05)$ difference between results obtained in 2 and $4 \mathrm{mM}\left[\mathrm{Ca}^{2+}\right]_{o}$.

\subsection{3. $\left[\mathrm{Ca}^{2+}\right]_{i}$ dependent effect of $I_{K 1}$ on repolarization reserve}

If $\mathrm{I}_{\mathrm{K} 1}$ was really increased by elevation of $\left[\mathrm{Ca}^{2+}\right]_{\mathrm{o}}$ (and consequently $\left[\mathrm{Ca}^{2+}\right]_{\mathrm{i}}$ ), contribution of $\mathrm{I}_{\mathrm{K} 1}$ to the repolarization reserve should also be increased under these conditions. This implicates that the lengthening effect of suppression of another $\mathrm{K}^{+}$current is expected to be smaller in high than in low $\left[\mathrm{Ca}^{2+}\right]_{\mathrm{o}}$. Indeed, as shown in Fig.12.D-F, 0.3 $\mu \mathrm{M}$ dofetilide, known to fully block $\mathrm{I}_{\mathrm{Kr}}$, caused significantly smaller lengthening of $\mathrm{APD}_{90}$ when the preparation was exposed to dofetilide in the presence of $4 \mathrm{mM}$ instead of $2 \mathrm{mM}$ $\left[\mathrm{Ca}^{2+}\right]_{0}$. The finding that dofetilide induced APD lengthening was attenuated at high $\left[\mathrm{Ca}^{2+}\right]_{0}$ is crucially important, since it also indicates that the high $\left[\mathrm{Ca}^{2+}\right]_{0}$-induced $\mathrm{AP}$ shortening cannot be related to faster activation of $\mathrm{I}_{\mathrm{Kr}}$ due to the elevated plateau potential. 


\subsection{4. $\left[\mathrm{Ca}^{2+}\right]_{\mathrm{i}}$ dependent modulation of steady-state $I_{K 1}$}

The possible effect of $\left[\mathrm{Ca}^{2+}\right]_{\mathrm{i}}$ on $\mathrm{I}_{\mathrm{K} 1}$ was investigated by comparing the effect of low $(\sim 160 \mathrm{nM})$ and high $(\sim 900 \mathrm{nM})\left[\mathrm{Ca}^{2+}\right]_{\mathrm{i}}$ directly on $\mathrm{I}_{\mathrm{K} 1}$ current by applying an appropriate mixture of $\mathrm{CaCl}_{2}$ and $\mathrm{Ca}^{2+}$ chelator BAPTA. The $\mathrm{Ca}^{2+}$ levels in the pipette solution were verified by a $\mathrm{Ca}^{2+}$ sensitive electrode. The steady-state current was determined as the $\mathrm{Ba}^{2+}$ sensitive current at the end of $300 \mathrm{~ms}$ long rectangular voltage pulses ranging between -80 and $-30 \mathrm{mV}$ arising from a holding potential of $-80 \mathrm{mV}$ (Fig. 13.A-B). The amplitude of $\mathrm{I}_{\mathrm{K} 1}$ was significantly augmented by high $\left[\mathrm{Ca}^{2+}\right]_{\mathrm{i}}$ between -70 and $-40 \mathrm{mV}(\mathrm{p}<0.05)$.

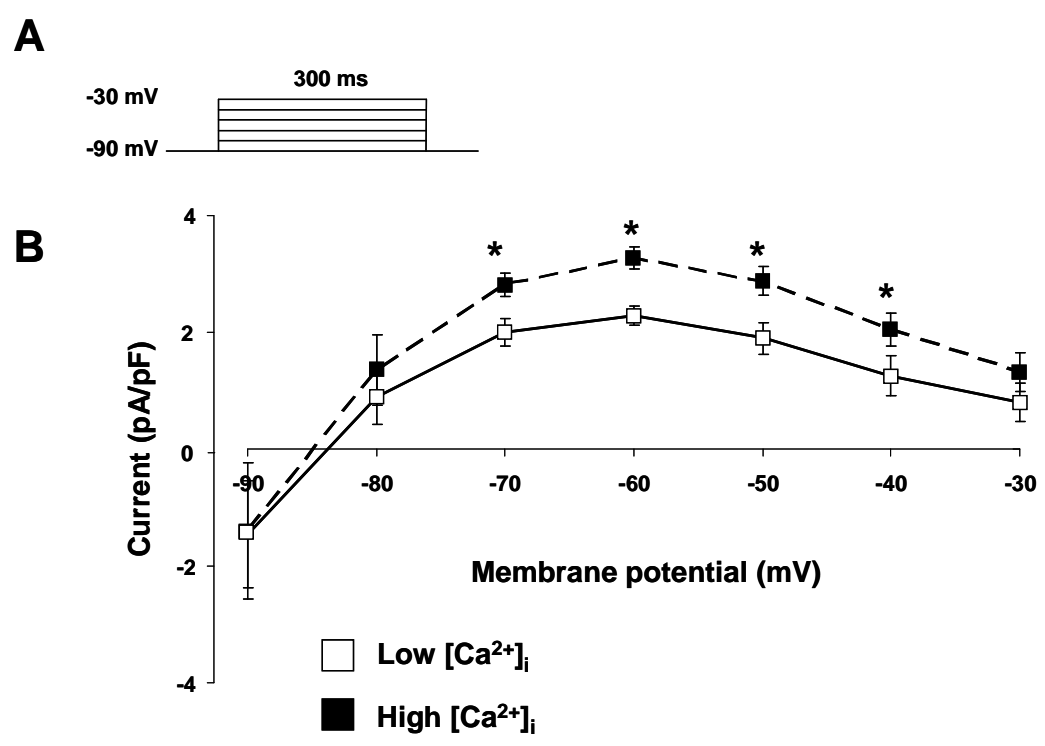

Fig.13. A-B Dependence of $I_{K I}$ on $\left[\mathrm{Ca}^{2+}\right]_{i}$ measured in canine single myocytes. $\mathrm{Ca}^{2+}$ concentrations were set in the pipette solution by WinMaxC software. Current-voltage relation was obtained by plotting the steady-state current against the membrane potential. Symbols and bars are means \pm SEM, asterisks denote significant $(p<0.05)$ differences between results of low $(n=9)$ and $\operatorname{high}(n=10)\left[\mathrm{Ca}^{2+}\right]_{i}$.

\subsubsection{Determination of the instantaneous $I_{K 1}$ current during an AP}

In this set of experiments the instantaneous $\mathrm{I}_{\mathrm{K} 1}$ current was determined during an AP used as command potential. $\mathrm{I}_{\mathrm{K} 1}$ was again dissected from the total current by applying 10 $\mu \mathrm{M} \mathrm{BaCl}$. Applying high $\left[\mathrm{Ca}^{2+}\right]_{\mathrm{i}}$ in the pipette solution significantly increased the peak current, while the activation kinetics of the current remained unchanged (Fig. 14.A-C). Furthermore, the I-V curve was slightly shifted toward positive direction when elevated $\left[\mathrm{Ca}^{2+}\right]_{\mathrm{i}}$ was applied in the pipette solution (from $-65 \pm 1.1$ to $-57 \pm 1.3 ; \mathrm{p}<0.05$ ) (Fig. 14.D). 

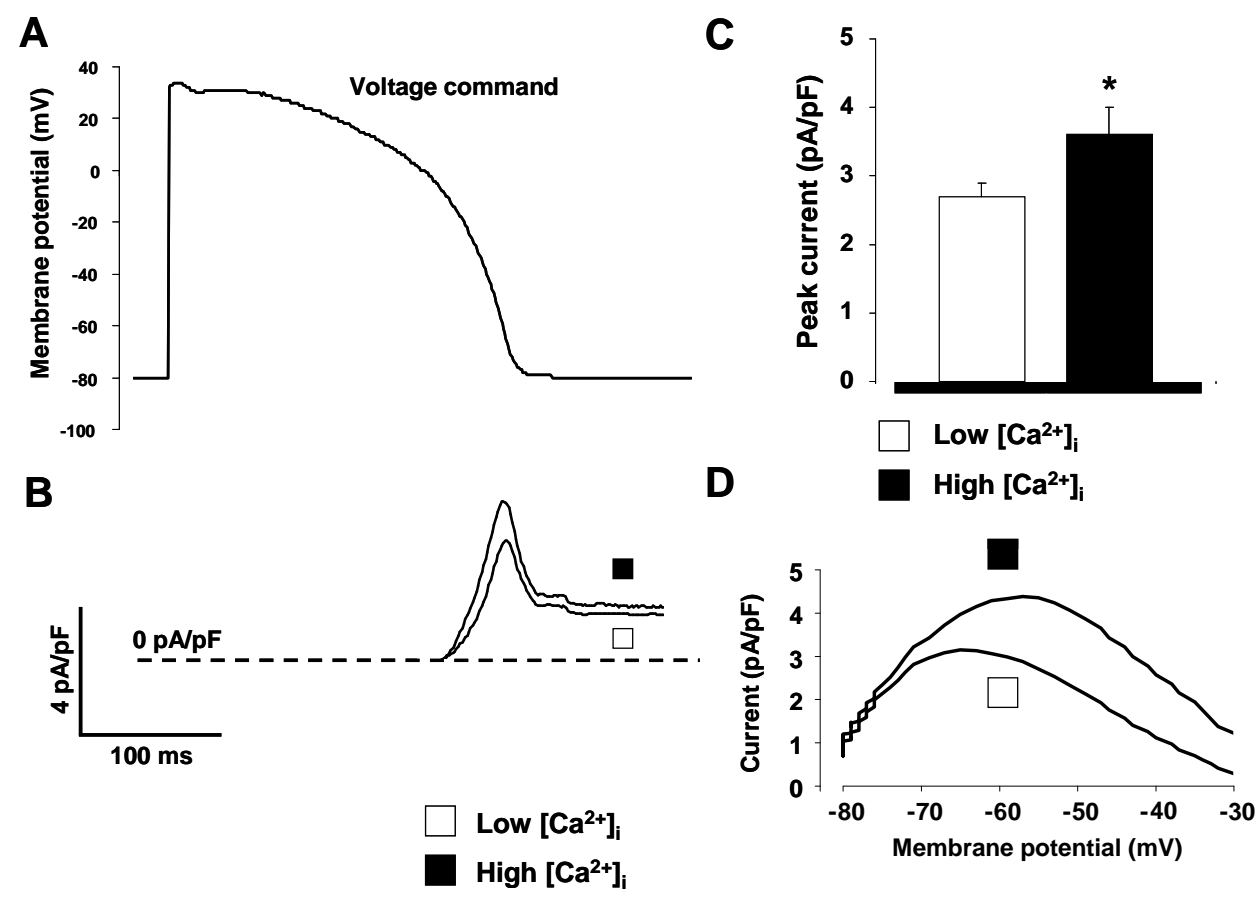

Fig.14. $\left[\mathrm{Ca}^{2}\right]_{i}$ dependence of $I_{K 1}$ measured by AP as a command potential $(\boldsymbol{A})$. The peak current was markedly increased when high $\left[\mathrm{Ca}^{2+}\right]_{i}$ was applied $(\boldsymbol{B}-\boldsymbol{C})$. The obtained current was plotted against the applied voltage command. Symbols and bars are means \pm SEM, asterisks denote significant $(p<0.05)$ differences between results of low $(n=9)$ and high $(n=10)\left[\mathrm{Ca}^{2+}\right]_{i}$. The $\mathrm{Ca}^{2+}$ induced $I_{K 1}$ enhancement was also plotted against the respective membrane potential. Currentvoltage relationship composed by plotting the instantaneous $I_{K 1}$ current against the corresponding AP voltages, denoted in panel $\boldsymbol{D}(p<0.05, n=7)$.

\subsubsection{Effect of dynamic increase of $\left[\mathrm{Ca}^{2+}\right]_{i}$ on steady state $I_{K 1}$}

Finally we tested the hypothesis that dynamic increase in $\left[\mathrm{Ca}^{2+}\right]_{\mathrm{i}}$, i.e. when CaTs were evoked during each cycle, may augment the $\mathrm{I}_{\mathrm{K} 1}$. The currents dissected by $10 \mu \mathrm{M}$ $\mathrm{BaCl}_{2}$ were compared in the presence and absence of dynamic $\mathrm{Ca}^{2+}$ elevation. The voltage protocol (Fig. 15.A) started with a brief, $50 \mathrm{~ms}$ long prepulse from $-80 \mathrm{mV}$ to $0 \mathrm{mV}$ in order to trigger $\mathrm{CaT}$ before current activation.

In the presence of $\mathrm{Ca}^{2+}$ buffering neither $\mathrm{CaT}$ nor current activation could be observed. In contrast, when dynamic $\mathrm{Ca}^{2+}$ elevation was allowed, $\mathrm{I}_{\mathrm{K} 1}$ increased markedly (Fig. 15.B). When $\left[\mathrm{Ca}^{2+}\right]_{\mathrm{i}}$ was low, the $\mathrm{I}-\mathrm{V}$ curve of $\mathrm{I}_{\mathrm{K} 1}$ was moderate, however, when EGTA was omitted from the pipette, the magnitude of the current was, again, considerably augmented between -70 to $-30 \mathrm{mV}(\mathrm{p}<0.05)$ (Fig. 15.C). 

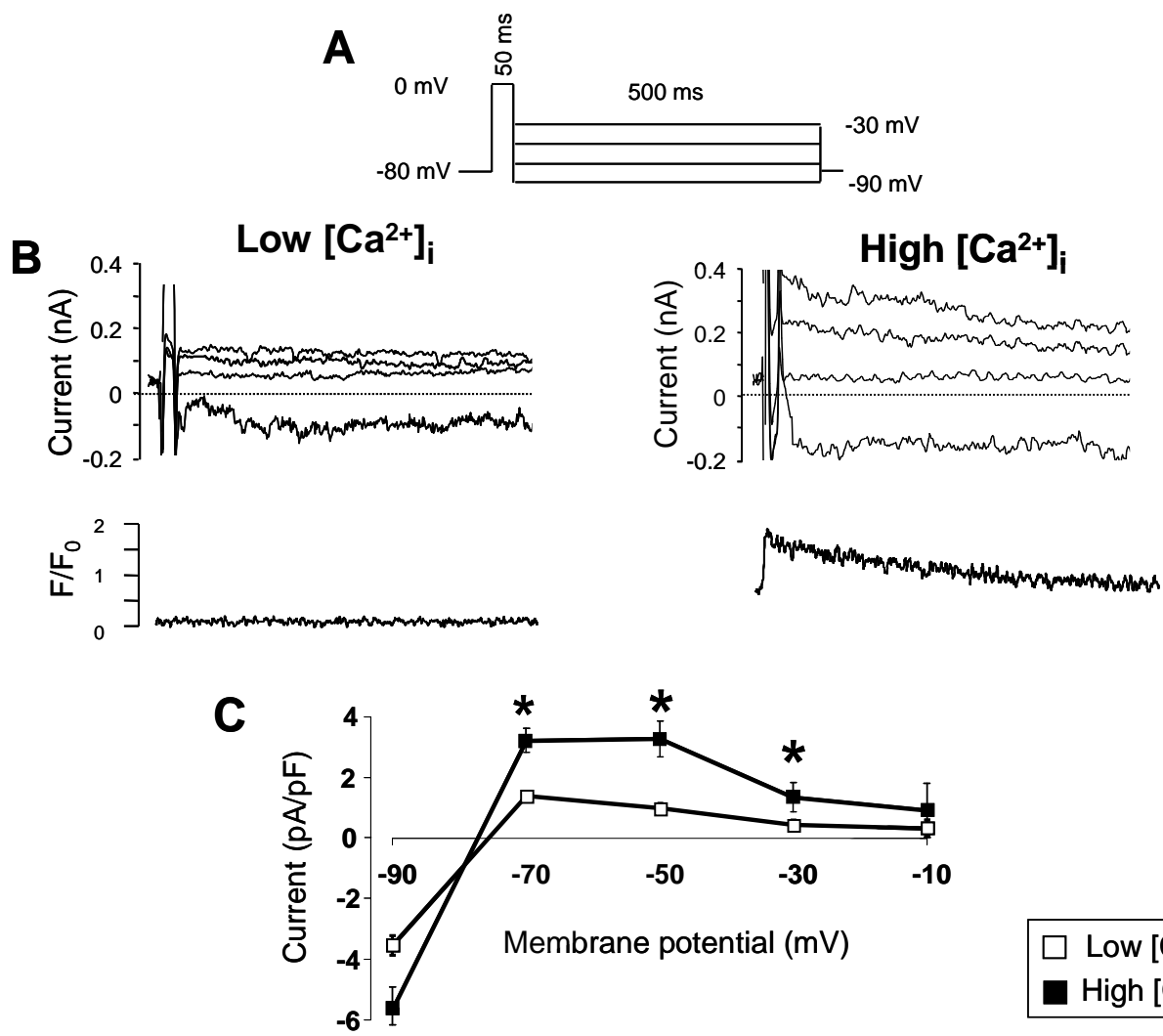

Fig.15. Dependence of $I_{K 1}$ on $\left[\mathrm{Ca}^{2+}\right]_{i}$. CaTs recorded under high $\left[\mathrm{Ca}^{2+}\right]_{i}$ conditions (no EGTA in the patch pipette) and low $\left[\mathrm{Ca}^{2+}\right]_{i}$ conditions (nominally $\mathrm{Ca}^{2+}$-free extracellular fluid and $5 \mathrm{mM}$ EGTA in the patch pipette) from isolated canine ventricular myocytes. (A) The voltage protocol: To evoke CaT the protocol started with $50 \mathrm{~ms}$ long prepulse from a holding potential of $-80 \mathrm{mV}$ to $0 \mathrm{mv}$. Steady state $I_{K I}$ current-voltage relationship has been determined by a series of $500 \mathrm{~ms}$ test pulses clamped to $-90,-70,-50$ and $-30 \mathrm{mV}$, respectively. In order to dissect $I_{K 1}$ the protocol was repeated in the presence of $10 \mu \mathrm{MBaCl}{ }_{2}$. (B) Representative sets of $I_{K 1}$ records and relative Fluo 4 fluorescence with (left panel) and without (right panel) $5 \mathrm{mM}$ EGTA in the pipette solution. (C) Superimposed current-voltage relationship with (open symbol) and without (filled symbol) evoked CaTs $(*=p<0.05 ; n=5)$. 


\section{DISCUSSION}

\subsection{Novel findings}

In this thesis several aspects of the interactions between cardiac repolarization and intracellular $\mathrm{Ca}^{2+}$ handling are summarized. In the corresponding studies we attempted to collect novel information on the level of modulation of the cardiac AP by changes in $\left[\mathrm{Ca}^{2+}\right]_{\mathrm{i}}$, primarily focusing at the repolarization process. Two well known $\mathrm{Ca}^{2+}$-dependent $\mathrm{K}^{+}$currents were investigated in details: 1 ) the small conductance $\mathrm{Ca}^{2+}$ activated $\mathrm{K}^{+}$current $\left(\boldsymbol{I}_{S K}\right)$, and 2). the inward rectifier $\mathrm{K}^{+}$current $\left(\boldsymbol{I}_{\boldsymbol{K} 1}\right)$. The results of the first study led us to the conclusion that the $\mathrm{I}_{\mathrm{SK}}$ has no apparent role in the physiological repolarization process. Nonetheless, the potential contribution of this current to accelerated repolarization in certain pathological conditions cannot be ruled out. In the other study we conclude that the magnitude of $I_{K 1}$ is significantly enhanced, when $\left[\mathrm{Ca}^{2+}\right]_{\mathrm{o}}$ (and consequently $\left[\mathrm{Ca}^{2+}\right]_{\mathrm{i}}$ ) is largely elevated.

\section{2. $\mathrm{Ca}^{2+}$ dependence of AP morphology}

A number of recently and formerly published data has provided strong evidence that under certain circumstances $\left[\mathrm{Ca}^{2+}\right]_{\mathrm{i}}$, directly or indirectly, exerts an important modulatory effect on AP morphology. $\mathrm{Ca}^{2+}$-induced alterations in the kinetics of the AP may be initiated by highly complex mechanisms and may be developed simultaneously via multiple effects of $\left[\mathrm{Ca}^{2+}\right]_{i}$ changes on a wide variety of individual ion channel types.

\subsubsection{Depolarizing currents}

The $\mathrm{Na}^{+}$current $\left(\mathrm{I}_{\mathrm{Na}}\right)$ activates and inactivates within a few milliseconds, however, the $\mathrm{Na}^{+}$influx does not vanish completely during the plateau phase. In the limited range of membrane potentials where activation and inactivation curves of the $\mathrm{I}_{\mathrm{Na}}$ overlap, a small persistent $\mathrm{Na}^{+}$current could be observed (late sodium current, $\mathrm{I}_{\mathrm{NaL}}$ ). The slow inactivation or 'window current' may still provide a significant amount of $\mathrm{Na}^{+}$ions, which can modulate $\mathrm{Ca}^{2+}$ handling via the reverse activity of NCX. This effect might be enhanced during heart failure, when AP plateau is prolonged and $\mathrm{I}_{\mathrm{NaL}}$ is increased. The gating of $\mathrm{I}_{\mathrm{Na}}$ may also be modulated by $\left[\mathrm{Ca}^{2+}\right]_{\mathrm{i}}$, however, the exact mechanism (i.e. via direct $\mathrm{Ca}^{2+}$ binding to the channel or via the CaM/CaMKII pathway) is not yet fully clarified. Tan et al [19] reported that CaM slows the inactivation of $\mathrm{I}_{\mathrm{Na}}$, while Kim et al [20] found that CaM 
modulates the $\mathrm{C}$-terminus of the channel, minimizing the sustained current component during depolarization, thus preventing arrhythmias. Wagner et al [21] found that in CaMKIII overexpressed rabbit heart slowered $\mathrm{I}_{\mathrm{Na}}$ inactivation enhanced the current. Maltsev [22] reported that all proposed modulatory pathways (Ca/CaM/CaMKII) might be responsible for the modulation of the $\mathrm{Na}^{+}$-channel: CaMKII slows the decay of $\mathrm{I}_{\mathrm{NaL}}$, while $\left[\mathrm{Ca}^{2+}\right]_{\mathrm{i}}$ shifts the steady-state inactivation level towards more positive potentials.

The L-type $\boldsymbol{C a}^{2+}$ current $\left(\boldsymbol{I}_{\boldsymbol{C a}}\right)$ is known to provide the main current for maintaining the plateau phase of the AP. Furthermore, it serves as the primary entry point for $\mathrm{Ca}^{2+}$ to induce ECC. [11, 23]. The gating of the current is directly controlled by $\mathrm{Ca} / \mathrm{CaM}$ during the $\mathrm{Ca}^{2+}$-dependent inactivation (CDI) [24]. Via limiting $\mathrm{Ca}^{2+}$ entry through the channel, $\mathrm{CDI}$ is a major component of the autoregulation of intracellular $\mathrm{Ca}^{2+}$ handling, through which the cardiomyocyte controls its $\left[\mathrm{Ca}^{2+}\right]_{\mathrm{i}}$, as well as the duration of the plateau phase. In turn, the $\mathrm{Ca} / \mathrm{CaM}$ complex indirectly increases $\mathrm{I}_{\mathrm{CaL}}$ via the activation of CaMKII. This effect can be functionally seen as a positive staircase phenomenon: i.e. $\mathrm{I}_{\mathrm{CaL}}$ amplitude increases and its inactivation slows down upon repetitive stimuli following a resting interval. This mechanism termed $\mathrm{Ca}^{2+}$-dependent facilitation (CDF) [24]. CDF and CDI functionally coexist in myocytes, however, while the CDI operates rapidly (during the same beat) the CDF develops beat-by-beat [12]. The modulatory effect of CaMKII on $\mathrm{I}_{\mathrm{CaL}}$ can also be involved in arrhythmogenesis: increased activity of CaMKII enhances the open probability of $\mathrm{I}_{\mathrm{CaL}}$, consequently, it increases the probability of triggered activity by EAD formation $[25,26]$.

\subsubsection{Repolarizing currents}

The suggested direct/indirect relationship between $\mathrm{Ca}^{2+}$ handling and repolarization raises interesting and important speculations: (i) beat-to-beat alterations in $\left[\mathrm{Ca}^{2+}\right]_{\mathrm{i}}$ may dynamically modulate the repolarization kinetics and may also significantly modulate the interaction between individual repolarizing $\mathrm{K}^{+}$currents (i.e. the repolarization reserve) (ii) physiological, frequency-dependent $\left[\mathrm{Ca}^{2+}\right]_{\mathrm{i}}$ changes may also substantially contribute to the rate-dependent APD alterations (iii) severely perturbed or impaired $\left[\mathrm{Ca}^{2+}\right]_{\mathrm{i}}$ handling, rather common in cardiac diseases, may disturb normal repolarization (iv) Under high $\left[\mathrm{Ca}^{2+}\right]_{\mathrm{i}}$ conditions the effect of certain class III. antiarrhythmic agents may be modified.

A simple and effective direct $\left[\mathrm{Ca}^{2+}\right]_{\mathrm{i}}$-dependent modulation of the repolarization kinetics can be established via the $\left[\mathrm{Ca}^{2+}\right]_{\mathrm{i}}$ dependent $\mathrm{K}^{+}$channels $\left(\mathrm{I}_{\mathrm{KCa}}\right)$ [27]. Another, 
similarly feasible alternative mechanism might be a modulatory effect of $\left[\mathrm{Ca}^{2+}\right]_{\mathrm{i}}$ on several $\mathrm{K}^{+}$currents $\left(\mathrm{I}_{\mathrm{to}}, \mathrm{I}_{\mathrm{Kr}}, \mathrm{I}_{\mathrm{Ks}}, \mathrm{I}_{\mathrm{K} 1}\right)$. Although the major kinetic properties and functional role of these repolarizing $\mathrm{K}^{+}$currents are well characterized ([3-6] the putative $\left[\mathrm{Ca}^{2+}\right]_{\mathrm{i}}$-sensitive regulation of the repolarization process is poorly elucidated.

\subsubsection{Direct link between repolarization and $\mathrm{Ca}^{2+}$ handling}

For several ion channels carrying important repolarizing currents, the primary signal for opening is an shift in $\left[\mathrm{Ca}^{2+}\right]_{\mathrm{i}} / \mathrm{CaM}$ activity. Furthermore, a few $\left[\mathrm{Ca}^{2+}\right]_{\mathrm{i}}$-induced downstream messengers may also contribute to channel gating. $\mathrm{Ca}^{2+}$ sensitivity and voltage dependency of these channels were found to be substantially channel type dependent and largely variable.

$\mathbf{C a}^{2+}$-activated $\mathbf{C l}^{-}$channels $\left(\boldsymbol{I}_{\mathbf{C l}(\mathbf{C a})}\right)$ are present in Purkinje cells and ventricular cardiomyocytes of canine and rabbit hearts [28, 29]. The estimated reversal potential for these channels is about $-60 \mathrm{mV}$, therefore, during the $\mathrm{AP}$ a small inward current is followed by an outward current. Since $\mathrm{Ca}^{2+}$ activated, this $\mathrm{Cl}^{-}$current follows the time course of the CaT and can be inhibited by blocking either the $\mathrm{Ca}^{2+}$ influx or the $\mathrm{Ca}^{2+}$ release from the SR [30]. The current is suggested to be primarily involved in phase 1 repolarization, thus it is often referred as $\mathrm{I}_{\mathrm{to} 2}$. Recent studies found that $\mathrm{I}_{\mathrm{Ca}(\mathrm{Cl})}$, at least to some extent, contribute to afterdepolarizations [31] .

$\mathrm{Ca}^{2+}$-activated $\mathrm{K}^{+}$channels $\left(\boldsymbol{I}_{\boldsymbol{K}(\boldsymbol{C a})}\right)$ are abundantly expressed in noncardiac tissues, including brain, peripheral nerves, skeletal muscle, vascular endothelium, liver, kidney, and were also suggested to be abundantly expressed and being active in the heart [32]. These channels are mainly classified by their open-state conductance: i.e. large (BK), [33] intermediate (IK), [34] and small conductance (SK) [35] channels have been identified. All SK channels show high $\mathrm{Ca}^{2+}$-sensitivity but weak voltage-dependence and varying sensitivity to apamin, an inhibitor toxin isolated from bee venom [34,36]. Based on their apamin-sensitivity there are three major SK channel subtypes: SK1 channels are little affected, SK2 channels are highly sensitive and SK3 channels are considered to be intermediate type $[34,36]$. Expression of all three subtypes of SK channels were demonstrated in various cardiac preparations including rat, murine and human hearts [34, 36], however, their functional role in the cardiac repolarization process has not been extensively studied and, therefore, is poorly understood. 


\subsubsection{Indirect interactions via main repolarizing currents $\left(I_{t_{0}}, I_{K r}, I_{K s}\right)$}

Depending on species and tissue type the $\mathbf{C a}^{2+}$-independent transient outward $\mathbf{K}^{+}$ current $\left(\mathbf{I}_{\mathbf{t o}}\right)$ has important role in phase 1 repolarization. Despite its transient nature, $\mathrm{I}_{\mathrm{to}}$ influences the APD and the plateau potential, therefore, it also has an indirect impact on $\mathrm{Ca}^{2+}$ handling. Tessier et al [37] reported that CaMKII slows the inactivation of $\mathrm{I}_{\mathrm{to}}$ in human atrial myocytes, therefore, it may contribute to development of atrial fibrillation. In HEK-293 cells the inactivation of Kv1.4 channels was slower following the activation of CaMKII [38]. A further study suggests that CaMKII acts directly on Kv4.3 by prolonging the open state inactivation and accelerating the rate of recovery from inactivation [39]. The studies show that CaMKII induced modulation of $\mathrm{I}_{\text {to }}$ may shorten the APD, furthermore, it might have an indirect effect on the $\mathrm{Ca}^{2+}$ handling via controlling the plateau potential [40]. PKC increases the inactivation time and slows the time course of recovery from inactivation [41].

The rapid component of the delayed rectifier $\mathbf{K}^{+}$current $\left(\mathbf{I}_{\mathbf{K r}}\right)$ is mediated by the KCHN2 (HERG: human ether-a-go-go-related gene) channel protein which can be modulated via activation of $\beta$ - and/or $\alpha$-adrenergic receptors or rising the intracellular cAMP level. PKA-induced phosphorylation reduces the amplitude of the HERG current and shifts the activation curve of $\mathrm{I}_{\mathrm{Kr}}$ towards depolarization [42, 43]. Isoproterenol enhances $\mathrm{I}_{\mathrm{Kr}}$ in guinea-pig and rabbit sinoatrial cells [44, 45]. Furthermore, in canine ventricular myocytes the magnitude of $\mathrm{I}_{\mathrm{Kr}}$ was also found to be enhanced by PKA [46], showing that modulation of $\mathrm{I}_{\mathrm{Kr}}$ by PKA is species and tissue dependent. The KCNH2 channels are also modulated by PKC via shifting the activation curve to positive direction and reducing the current [47]. In contrast, during $\beta$-adrenoreceptor stimulation Terrar et al. [48] found PKC-induced increase in the amplitude of $\mathrm{I}_{\mathrm{Kr}}$. Direct $\left[\mathrm{Ca}^{2+}\right]_{\mathrm{i}} / \mathrm{CaM} / \mathrm{CaMKII}$ mediated $\mathrm{I}_{\mathrm{Kr}}$ modulation has not been reported, so far.

The slow component of the delayed rectifier $\mathbf{K}^{+}$current $\left(\mathbf{I}_{\mathrm{Ks}}\right)$, generated by the KvLQT1+MinK+MIRP channel complex, is enhanced by $\beta$-adrenoreceptor activation, $\alpha$ adrenerg stimulation, PKC phosphorylation, or rise in $\left[\mathrm{Ca}^{2+}\right]_{\mathrm{i}} \cdot \beta$-adrenoreceptor activation increases PKA activity, which enhances the amplitude of $\mathrm{I}_{\mathrm{Ks}}$ and causes rate dependent shortening of APD [49]. PKA phosphorylation of the channels markedly enhances the amplitude of $\mathrm{I}_{\mathrm{Ks}}$ by increasing the rate of activation of the channel, and by reducing its rate of deactivation [50]. Lowering $\left[\mathrm{K}^{+}\right]_{\mathrm{o}}$ and $\left[\mathrm{Ca}^{2+}\right]_{\mathrm{o}}$ also increases $\mathrm{I}_{\mathrm{Ks}}$ [51]. In contrast, endothelin-1 reduces $\mathrm{I}_{\mathrm{Ks}}$, presumably via the inhibition of the adenylate-cyclase [52]. 
The inward rectifier $\mathbf{K}^{+}$current $\left(\mathbf{I}_{\mathbf{K} 1}\right)$ is a composite current generated by a complex population of Kir 2.1, 2.2, 2.3 and possibly TASK-1 and TWIK-1 channels, and is primarily responsible for the terminal phase of the repolarization process. It also has a pivotal role in stabilizing the resting membrane potential [53]. Data in the literature are highly controversial on the nature of its $\left[\mathrm{Ca}^{2+}\right]_{\mathrm{i}}$ dependence, therefore, one of our primary goals was to investigate the modulatory effect of $\left[\mathrm{Ca}^{2+}\right]_{\mathrm{i}}$ on $\mathrm{I}_{\mathrm{K} 1}$. The review of previous studies and the results and conclusions of our experiments are discussed in chapter 4.4.

\subsection{Are there functioning SK channels in mammalian myocardium?}

Based on their high $\mathrm{Ca}^{2+}$-sensitivity and relatively weak voltage-dependence, one could expect that SK channels provide an important functional direct link between $\mathrm{Ca}^{2+}$ handling and the electrical events of the surface membrane. Thus, these channels might modify AP configuration by responding to beat-to-beat alterations of $\left[\mathrm{Ca}^{2+}\right]_{\mathrm{i}}$.

\subsubsection{Previous results}

In a previous study $\mathrm{Xu}$ et al. found that SK channel blockade by apamin (50 pM) significantly lengthened the APD in murine atrial and ventricular myocytes and also in human atrial cells [36]. Implications of these observations may be very important, since the reported apamin-sensitive, marked lengthening of the APD suggests a crucial involvement of the SK channels in the physiological repolarization process. In addition, based on the observation that the APD is lengthened by its inhibition, modulation of $\mathrm{I}_{\mathrm{SK}}$ may represent a novel antiarrhythmic mechanism, which could initiate novel pharmacological strategies. Furthermore, SK channels can be expected to substantially contribute to the repolarization reserve, especially during $\mathrm{Ca}^{2+}$ overload. Based on data from genetically altered mouse models, SK channels may have functional importance in development of atrial fibrillation [54] and in the kinetics of the AV node APs [55].

\subsubsection{Has any role SK current in cardiac repolarization?}

Based on classical molecular biologic techniques, we also verified the expression and mostly plasmamembrane location of the SK2 channels, however, in contrast to findings by $\mathrm{Xu}$ et al [36], we failed to identify any apamin induced alteration either in ventricular or in atrial AP, as well as in the corresponding ion currents, in either species, studied. The major discrepancy between their and our results may either derive from interspecies differences, or from partially different experimental conditions. Perhaps the most important difference 
can be found in the AP measurements. The AP measurements by Xu et al [36] were carried out in single isolated cardiomyocytes, while ours were performed in multicellular cardiac tissue using the conventional microelectrode technique. Recording APs from single isolated cells is a widely used/accepted technique, however, it may not be fully suitable for detection of small changes in APD, since the enzymatic dissociation process may result in compromised repolarization reserve. During isolation, a varying portion of $\mathrm{K}^{+}$channels are impaired, resulting in suppressed $\mathrm{K}^{+}$currents, quite similar to nonspecific $\mathrm{K}^{+}$channel inhibition. This may lead to AP instability, unexpected time dependent changes and attenuation of the effect of an ion channel blocker.

An alternative explanation for the found discrepancy may be that the physiologically achieved $\left[\mathrm{Ca}^{2+}\right]_{\mathrm{i}}$ level increase is not sufficient to activate large enough SK current, which could overcome the strong repolarizing capacity of the ventricular muscle. To clarify this possibility we attenuated the repolarizing reserve by inhibiting major repolarizing currents ( $\mathrm{I}_{\mathrm{Kr}}$ in the dog, $\mathrm{I}_{\mathrm{Kur}}$ plus $\mathrm{I}_{\mathrm{to}}$ in the rat) prior to apamin administration. As expected, these interventions markedly lengthened the APD in both species, however, subsequently applied apamin still failed to induce any further APD prolongation, suggesting negligible role for apamin-sensitive SK-current in cardiac ventricular repolarization [56].

Based on computer modelling studies of the rabbit ventricular AP [57], NCX should primarily operate in forward mode (i. e. carrying an inward current) during a plateau-type AP. Inhibition of this current may lead to APD prolongation. In AP measurements, further to the repolarization reserve, the NCX current - the direction of which is opposite to the SK-current and at the same time it is also $\left[\mathrm{Ca}^{2+}\right]_{\mathrm{i}}$ governed - may also substantially complicate the evaluation of the effect of SK-current inhibition.

Nonetheless, it still remained unclear, whether the suppression of the NCX current would influence the APD in the presence of intact repolarization reserve. Despite a marked impact of SEA0400 - a selective NCX antagonist - on the NCX current, the kinetics of the AP remained practically unaltered in both canine and rabbit multicellular preparations. This fact may indicate a relatively small inward NCX current in a normal plateau type AP. In line with these observations, no significant effect on canine CaT following the application SEA0400 was observed [58]. Neither NCX inhibition was able to suppress the incidence of dofetilide-induced torsade de pointes in rabbit [59].

Interestingly, in rat cardiomyocytes, in spite of the SEA0400 induced positive inotropic effect (demonstrated by simultaneous $\mathrm{CaT}$ and cell shortening measurements [60, 
61]), the AP, again, did not change, thus suggesting a much larger impact of NCX activity on $\mathrm{Ca}^{2+}$ handling than on AP kinetics.

A set of measurements were also performed in order to study the possible modulatory role of $\left[\mathrm{Ca}^{2+}\right]_{\mathrm{i}}$ alterations on the apamin effect. Our fluorometric measurements revealed that in canine cardiomyocytes the highest $\left[\mathrm{Ca}^{2+}\right]_{\mathrm{i}}$ levels could be reached at $3 \mathrm{~Hz}$, while in rat ventricular myocytes at $0.3 \mathrm{~Hz}$ stimulation rate. No frequency-dependent differences in AP kinetics following apamin administration could be observed, suggesting that even the highest physiological $\left[\mathrm{Ca}^{2+}\right]_{\mathrm{i}}$ levels might still be too low to activate the SK channels.

In a set of further experiments we attempted to directly identify the apamin sensitive current in voltage clamped single canine and rat cardiomyocytes. However, application of $100 \mathrm{nM}$ apamin failed to cause any shift of the control I-V curve in either species, again suggesting the lack of functional apamin-sensitive $\mathrm{K}^{+}$channels in ventricular myocardium. The lack of effect of apamin in our patch clamp experiments was unexpected, since Xu et al. [36] reported rather large apamin-sensitive current $(4 \mathrm{pA} / \mathrm{pF})$ in the membrane potential range corresponding to the AP plateau.

The perforated patch clamp technique allows the preservation of the intracellular milieu of the cell, while CaTs and cell contraction are evoked. Therefore, this setting allows to investigate, whether the SK current only responds to dynamic $\left[\mathrm{Ca}^{2+}\right]_{i}$ changes. However, $100 \mathrm{nM}$ apamin failed again to cause any shift in the I-V curve.

\subsubsection{What may be the message of our results?}

In contrast to previous reports, our data seem to contradict the significance of the previous observations made in mice and in human, and the reason of this discrepancy is not clear. We must conclude that SK channels play only negligible - if any - role in cardiac repolarization under physiological conditions. However, the possibility that these channels may activate under a few special circumstances (such as $\mathrm{Ca}^{2+}$ overload, heart failure, or conditions of ischemia/reperfusion) cannot be ruled out. Our data may also have important implications regarding pharmacological speculations and future drug development. Further experiments are required to investigate the putative role of the SK channels in diseased myocardium, before its pharmacological modulation could be utilized. 


\section{4. $\mathrm{Ca}^{2+}$ dependence of $\mathrm{I}_{\mathrm{K} 1}$}

$\mathrm{I}_{\mathrm{K} 1}$ is activated in the final phase of the repolarization process and sets and stabilizes the resting membrane potential. The current shows strong inward rectification, thus enables significantly larger inward than outward current. In outward direction, the current reduces close to zero at potentials positive than $-30 \mathrm{mV}$, then quickly reopens when membrane potential approximates more negative values. This feature is due to $\mathrm{Mg}^{2+}$ and polyamines (spermine and spermidine) induced channel block upon depolarization [53]. $\mathrm{I}_{\mathrm{K} 1}$ beyond being an important component of the repolarization reserve, also opposes any kind of arrhythmogenic depolarization occurring in rest, like the $\mathrm{Ca}^{2+}$ overload induced transient inward current $[4,53]$. Hence, any impairment of this current may be arrhythmogenic, since positive resting membrane potential shifts facilitate extrasystoles [4]. Furthermore, decreased $\mathrm{I}_{\mathrm{K} 1}$ lengthens APD and may increase the dispersion of repolarization, providing substrate for reentries [60]. Although partial blockade of $\mathrm{I}_{\mathrm{K} 1}$ by $10 \mu \mathrm{M} \mathrm{BaCl}_{2}$ substantially inhibits the current (about 70\% [4]) it only causes marginal APD lengthening. Therefore, under physiological conditions $\mathrm{I}_{\mathrm{K} 1}$ can be more considered as a component of the reserve than possessing major repolarizing role. Nevertheless, when repolarization reserve was attenuated, the effect of $\mathrm{I}_{\mathrm{K} 1}$ inhibition was found to be largely enhanced, indicating that in this circumstances $\mathrm{I}_{\mathrm{K} 1}$ can be a key player of the repolarization reserve [4].

\subsubsection{Is $\mathrm{I}_{\mathrm{K} 1}\left[\mathrm{Ca}^{2+}\right]_{\mathrm{i}}$-sensitive?}

Results from studies on $\mathrm{Ca}^{2+}$-dependency of $\mathrm{I}_{\mathrm{K} 1}$ are much controversial. Several early studies concluded that $\mathrm{Ca}^{2+}$ ions inhibit $\mathrm{I}_{\mathrm{K} 1}$ [62-65], while others found a positive relationship between $\left[\mathrm{Ca}^{2+}\right]_{\mathrm{i}}$ and $\mathrm{I}_{\mathrm{K} 1}$ [66-69]. Recently, Zaza et al. [70] have reported that the increase in $\left[\mathrm{Ca}^{2+}\right]_{\mathrm{i}}$ decreased the magnitude of $\mathrm{I}_{\mathrm{K} 1}$, though the functional significance of this effect remained unclarified. In rat myocytes Fauconnier et al. [71] also demonstrated that in heart failure, when diastolic $\left[\mathrm{Ca}^{2+}\right]_{\mathrm{i}}$ is elevated, $\mathrm{I}_{\mathrm{K} 1}$ is reduced. Wagner et al, [72] concluded that AP shortening by CaMKII overexpression in rabbit myocytes, is partially the consequence of CaMKII induced $\mathrm{I}_{\mathrm{K} 1}$ increasing. It is known that $\left[\mathrm{Ca}^{2+}\right]_{\mathrm{i}}$ is considerably raised and the AP is shortened during hypoxia [73]. According to the "classical" theory, this shortening is due to the activation of $\mathrm{K}_{\mathrm{ATP}}$ channels. However, several studies reported a substantial contribution of $\mathrm{I}_{\mathrm{K} 1}$ to this APD adaptation $[68,74-76]$, while Lopatin et al [68] found direct relationship between elevated $\left[\mathrm{Ca}^{2+}\right]_{\mathrm{i}}$ and $\mathrm{I}_{\mathrm{K} 1}$ activation during hypoxia in isolated mouse cardiomyocytes. 


\subsection{2. $\mathrm{I}_{\mathrm{K} 1}$ mediated $\left[\mathrm{Ca}^{2+}\right]_{\mathrm{i}}$ effects on $\mathrm{AP}$ morphology}

We investigated the putative $\mathrm{Ca}^{2+}$-dependence of $\mathrm{I}_{\mathrm{K} 1}$ under multicellular, as well, as single cell conditions. In the AP measurements we attempted to raise $\left[\mathrm{Ca}^{2+}\right]_{\mathrm{i}}$ as selectively as possible. To avoid activation of PKA and PKC, we did not use adrenergic agonists, thus the multiple effects of protein kinases may have averted. Instead, we increased $\left[\mathrm{Ca}^{2+}\right]_{0}$ to 4 $\mathrm{mM}$, thus enhancing the "driving force" for $\mathrm{Ca}^{2+}$ ions through the $\mathrm{I}_{\mathrm{CaL}}$. As expected, enhanced $\left[\mathrm{Ca}^{2+}\right]_{\mathrm{i}}$ markedly shortened $\mathrm{APD}_{90}$. Furthermore, the maximal velocity of the terminal repolarization was also found to be faster. This effect may be a consequence of decreased inward and increased outward currents. Enhanced inactivation of $\mathrm{I}_{\mathrm{CaL}}$ during high $\left[\mathrm{Ca}^{2+}\right]_{\mathrm{i}}$ conditions is a widely accepted mechanism underlying the AP shortening, however in the potential range of the terminal repolarization $\mathrm{I}_{\mathrm{CaL}}$ is already inactivated.

Increased repolarizing currents $\left(\mathrm{I}_{\mathrm{Kr}}, \mathrm{I}_{\mathrm{Ks}}, \mathrm{I}_{\mathrm{K} 1}\right)$ were also suggested to contribute to enhanced terminal repolarization, especially when APD shortening is paralleled by elevated plateau potential. Therefore, we tested the putative role of the delayed rectifiers $\left(\mathrm{I}_{\mathrm{Kr}}\right.$ and $\mathrm{I}_{\mathrm{Ks}}$ ) in high $\left[\mathrm{Ca}^{2+}\right]_{\mathrm{i}}$ induced APD shortening. Interestingly, selective inhibition of $\mathrm{I}_{\mathrm{Kr}}$ by dofetilide did not result in increased APD lengthening when $\left[\mathrm{Ca}^{2+}\right]_{\mathrm{o}}$ was elevated. In contrast, the effect of dofetilide was significantly reduced. Following selective inhibition of $\mathrm{I}_{\mathrm{Ks}}$ by HMR-1556 no effect could be observed. This results exclude a possible $\mathrm{I}_{\mathrm{Kr}}$ enhancement by elevated $\left[\mathrm{Ca}^{2+}\right]_{\mathrm{i}}$, however, the reduced effect of dofetilide may be a result of the shortened $\mathrm{APD}_{90}$ caused by high $\left[\mathrm{Ca}^{2+}\right]_{\mathrm{i}}$. APD abbreviation is able to reduce the effect of $\mathrm{I}_{\mathrm{Kr}}$ inhibition [77], however, it may only partially explain our findings, since under the same conditions the effect of $\mathrm{I}_{\mathrm{K} 1}$ inhibition was largely enhanced. An alternative explanation can be based on the concept of the repolarization reserve: i.e. the reduced effect of $\mathrm{I}_{\mathrm{Kr}}$ inhibition could also be the consequence of increased outward currents (e.g.: $I_{K 1}$, which is able to partially compensate for $I_{K r}$ inhibition.

In contrast to the negative results of $\mathrm{I}_{\mathrm{Kr}}$ and $\mathrm{I}_{\mathrm{Ks}}$ inhibition, the effect of $\mathrm{I}_{\mathrm{K} 1}$ inhibition was considerably increased by enhanced $\left[\mathrm{Ca}^{2+}\right]_{0}$ in canine papillary muscles.

\subsubsection{The effect of $\left[\mathrm{Ca}^{2+}\right]_{i}$ on $I_{K 1}$ current}

Since $I_{K 1}$ is permanently active during the late repolarization phase and the entire diastolic period, if $\mathrm{I}_{\mathrm{K} 1}$ was $\mathrm{Ca}^{2+}$-dependent, both systolic and diastolic $\left[\mathrm{Ca}^{2+}\right]_{\mathrm{i}}$ would affect the magnitude of the current. In these experiments $\mathrm{Ca}^{2+}$ dependency of $\mathrm{I}_{\mathrm{K} 1}$ was compared between the high and low $\left[\mathrm{Ca}^{2+}\right]_{i}$ groups and three sets of measurements were performed. In the first set steady-state currents were measured at the end of each voltage steps, in the 
second set the instantaneous currents were determined. Finally, in the third set the effect of dynamically increased $\left[\mathrm{Ca}^{2+}\right]_{\mathrm{i}}$ on the steady-state current was investigated. In all 3 sets of experiments $\mathrm{I}_{\mathrm{K} 1}$ was defined as the $\mathrm{Ba}^{2+}$ sensitive current.

Independent of the protocol used, following $\left[\mathrm{Ca}^{2+}\right]_{\mathrm{i}}$ rise the $\mathrm{Ba}^{2+}$-sensitive current was substantially increased between -70 to $-40 \mathrm{mV}$. The related data seem to support previous results reporting enhanced $\mathrm{I}_{\mathrm{K} 1}$ following $\left[\mathrm{Ca}^{2+}\right]_{\mathrm{o}}$ rise in Purkinje fibers, and during hypoxiainduced APD shortening, where $\mathrm{Ca}^{2+}$ dependent $\mathrm{I}_{\mathrm{K} 1}$ augmentation may contribute to APD adaptation. On the other hand, our results seem to oppose findings of studies describing $\mathrm{I}_{\mathrm{K} 1}$ amplitude reduction following $\left[\mathrm{Ca}^{2+}\right]_{\mathrm{i}}$ rise in isolated cardiac cells from various species and during various conditions. In early studies finding $\mathrm{I}_{\mathrm{K} 1}$ amplitude reduction the discrepancy may derive from the conditions applied, which were far from the physiological range. Zaza et al [70] reported $\mathrm{Ca}^{2+}$ induced rectification of $\mathrm{I}_{\mathrm{K} 1}$; i.e. lowering $\left[\mathrm{Ca}^{2+}\right]_{\mathrm{i}}$ increased the current. Nonetheless, all these findings could only be seen in a membrane potential range corresponding to the plateau phase of the AP, while the terminal repolarization remained unaltered. Finally in failing rat hearts Fauconnier et al. [71] reported reduced $I_{K 1}$ current, contributing to the elevated diastolic $\mathrm{Ca}^{2+}$. However, in heart failure upregulated $\mathrm{NCX}$ and downregulated SERCA activities were found to result in a substantial decrease in systolic $\left[\mathrm{Ca}^{2+}\right]_{\mathrm{i}}$. Therefore, it seems feasible that the overall $\left[\mathrm{Ca}^{2+}\right]_{\mathrm{i}}$ sensed by the corresponding ion channels of $I_{K 1}$ was indeed, decreased.

\subsubsection{Has $I_{K 1}$ multiple regulation?}

Several studies reported that beyond being regulated by $\left[\mathrm{Ca}^{2+}\right]_{\mathrm{i}}, \mathrm{I}_{\mathrm{K} 1}$ is also sensitive to alterations in the phosphorylation/dephosphorylation state of the channel proteins caused by a variety of protein kinases. Several studies reported that PKA, PKC and CaMKII may have distinct modulatory effects on $\mathrm{I}_{\mathrm{K} 1}$. During adrenerg stimulation PKA and PKC may reduce the amplitude of $\mathrm{I}_{\mathrm{K} 1}$, while CaMKII may augment the current. Indeed, it seems feasible that distinct modulatory pathways (PKA, PKC, CaMKII, $\left[\mathrm{Ca}^{2+}\right]_{\mathrm{i}}$ ) concomitantly target the corresponding channels and jointly fine-tune the amplitude of $\mathrm{I}_{\mathrm{K} 1}$ to improve the adaptation of the current to varying external conditions. Our results support the idea first suggested by Wagner et al [72], that under high $\left[\mathrm{Ca}^{2+}\right]_{\mathrm{i}}$ conditions $\mathrm{I}_{\mathrm{K} 1}$ is enhanced by CaMKII. Sympathetic stimulation activates the PKA and PKC pathways both exerting crucial role in controlling the shape of the AP via modulating a few ionic currents like $\mathrm{I}_{\mathrm{CaL}}$, $\mathrm{I}_{\mathrm{Ks}}$, and $\mathrm{I}_{\mathrm{Cl}}$. Nonetheless, their inhibiting effect on $\mathrm{I}_{\mathrm{K} 1}$ can be seriously arrhythmogenic via reducing the repolarization reserve and compromising the resting membrane potential. 
Therefore, simultaneous CaMKII activation and $\left[\mathrm{Ca}^{2+}\right]_{\mathrm{i}}$ increase may counteract and limit the PKA/PKC induced $\mathrm{I}_{\mathrm{K} 1}$ reduction, and thus prevent arrhythmia generation. Consequently, substantially different experimental conditions may cause the loss of the balance between these two counteracting pathways resulting in reduced $\mathrm{I}_{\mathrm{K} 1}$ amplitude. This explanation may help in understanding the contradicting results on $\mathrm{Ca}^{2+}$-sensitivity of $\mathrm{I}_{\mathrm{K} 1}$.

\subsubsection{What may be the message of our results?}

Overall, our data suggest that increased $\left[\mathrm{Ca}^{2+}\right]_{\mathrm{i}}$ may activate an autoregulative $\mathrm{I}_{\mathrm{K} 1}$ augmentation. Under conditions investigated, the enhancement in $\mathrm{I}_{\mathrm{K} 1}$ seems to be confined to the systolic period of the cardiac cycle. During diastole the resting membrane potential is practically not affected. Increased $\left[\mathrm{Ca}^{2+}\right]_{i}$ is a principal component of the cardiac adaptation process, however, it may also lead to increased probability of arrhythmogenesis. Therefore, when $\left[\mathrm{Ca}^{2+}\right]_{\mathrm{i}}$ is elevated, a compensatory feed-back increase in $\mathrm{I}_{\mathrm{K} 1}$ should have antiarrhytmic role via enhancing the repolarization reserve. Considering disparate results in the literature, we could not rule out any direct enhancing effect of $\left[\mathrm{Ca}^{2+}\right]_{\mathrm{i}}$ on $\mathrm{I}_{\mathrm{K} 1}$. Another possible mechanism for the $\left[\mathrm{Ca}^{2+}\right]_{\mathrm{i}}$-induced $\mathrm{I}_{\mathrm{K} 1}$ increase is via distinct activation of the CaMKII, as was also demonstrated previously [72]. Our results also suggest that elevated $\left[\mathrm{Ca}^{2+}\right]_{\mathrm{i}}$ may markedly influence the efficacy of class III antiarrhythmic drugs, counteracting their AP prolonging action. 


\section{CONCLUSIONS AND FURTHER PERSPECTIVES}

Our results support the presence of a $\mathrm{Ca}^{2+}$ activated $\mathrm{K}^{+}$current in the membrane potential range of the terminal repolarization. However, we had to conclude that this current may not be the SK-current, rather the $\mathrm{I}_{\mathrm{K} 1}$, which thus could improve the instantaneous adaptation of AP to an external challenge. Since $\mathrm{I}_{\mathrm{K} 1}$ cannot be related to one particular channel type, rather to a complex mixture of $\mathrm{Ba}^{2+}$ sensitive channels (primarily Kir2.x), active during terminal repolarization, we cannot exactly identify the primary $\mathrm{Ca}^{2+}$ sensitive ion channel(s).

We could not demonstrate an apamin sensitive $\mathrm{K}^{+}$current in cardiac ventricular muscle, and it is rather difficult to explain the obvious discrepancy between our results and data in the literature. However, considering the growing body of evidence on functional $\mathrm{Ca}^{2+}$ activated $\mathrm{K}^{+}$currents in the heart, and the relatively wide range of ion channels, which are inhibited by $\mathrm{Ba}^{2+}$, we cannot rule out the possibility that the "classical" $\mathrm{Ca}^{2+}$ activated $\mathrm{K}^{+}$current and the $\mathrm{Ca}^{2+}$ sensitive $\mathrm{I}_{\mathrm{K} 1}$, at least partially, overlap regarding the responsible ion channel(s). This hypothesis, however, requires further experimental work. 


\section{REFERENCES}

[1] Ravens U, Cerbai E. Role of potassium currents in cardiac arrhythmias. Europace. 2008 Oct; 10(10): 1133-7.

[2] Roden DM. Taking the "idio" out of "idiosyncratic": predicting torsades de pointes. Pacing Clin Electrophysiol. 1998 May; 21(5): 1029-34.

[3] Varro A, Balati B, Iost N, Takacs J, Virag L, Lathrop DA, et al. The role of the delayed rectifier component IKs in dog ventricular muscle and Purkinje fibre repolarization. J Physiol. 2000 Feb 15; 523 Pt 1: 67-81.

[4] Biliczki P, Virag L, Iost N, Papp JG, Varro A. Interaction of different potassium channels in cardiac repolarization in dog ventricular preparations: role of repolarization reserve. Br J Pharmacol. 2002 Oct; 137(3): 361-8.

[5] Jost N, Virag L, Bitay M, Takacs J, Lengyel C, Biliczki P, et al. Restricting excessive cardiac action potential and QT prolongation: a vital role for IKs in human ventricular muscle. Circulation. 2005 Sep 6; 112(10): 1392-9.

[6] Banyasz T, Magyar J, Szentandrassy N, Horvath B, Birinyi P, Szentmiklosi J, et al. Action potential clamp fingerprints of $\mathrm{K}+$ currents in canine cardiomyocytes: their role in ventricular repolarization. Acta Physiol (Oxf). 2007 Jul; 190(3): 189-98.

[7] Farkas AS, Nattel S. Minimizing repolarization-related proarrhythmic risk in drug development and clinical practice. Drugs. Mar 26; 70(5): 573-603.

[8] Antzelevitch C, Fish J. Electrical heterogeneity within the ventricular wall. Basic Res Cardiol. 2001 Nov; 96(6): 517-27.

[9] Eisner DA, Choi HS, Diaz ME, O'Neill SC, Trafford AW. Integrative analysis of calcium cycling in cardiac muscle. Circ Res. 2000 Dec 8; 87(12): 1087-94.

[10] Dibb KM, Graham HK, Venetucci LA, Eisner DA, Trafford AW. Analysis of cellular calcium fluxes in cardiac muscle to understand calcium homeostasis in the heart. Cell Calcium. 2007 Oct-Nov; 42(4-5): 503-12.

[11] Dibb KM, Eisner DA, Trafford AW. Regulation of systolic [Ca2+]i and cellular $\mathrm{Ca} 2+$ flux balance in rat ventricular myocytes by SR Ca2+, L-type $\mathrm{Ca} 2+$ current and diastolic [Ca2+]i. J Physiol. 2007 Dec 1; 585(Pt 2): 579-92.

[12] Bers DM. Excitation-contraction coupling and cardiac contractile force. Kluwer Academic Press. 2001.

[13] Choi HS, Eisner DA. The role of sarcolemmal Ca2+-ATPase in the regulation of resting calcium concentration in rat ventricular myocytes. J Physiol. 1999 Feb 15; 515 ( Pt 1): 109-18.

[14] O'Neill SC, Miller L, Hinch R, Eisner DA. Interplay between SERCA and sarcolemmal $\mathrm{Ca} 2+$ efflux pathways controls spontaneous release of $\mathrm{Ca} 2+$ from the sarcoplasmic reticulum in rat ventricular myocytes. J Physiol. 2004 Aug 15; 559(Pt 1): 121-8.

[15] Bers DM, Despa S, Bossuyt J. Regulation of $\mathrm{Ca} 2+$ and $\mathrm{Na}+$ in normal and failing cardiac myocytes. Ann N Y Acad Sci. 2006 Oct; 1080: 165-77.

[16] Nattel S, Maguy A, Le Bouter S, Yeh YH. Arrhythmogenic ion-channel remodeling in the heart: heart failure, myocardial infarction, and atrial fibrillation. Physiol Rev. 2007 Apr; 87(2): 425-56.

[17] Patton C, Thompson S, Epel D. Some precautions in using chelators to buffer metals in biological solutions. Cell Calcium. 2004 May; 35(5): 427-31.

[18] Bers DM. Calcium fluxes involved in control of cardiac myocyte contraction. Circ Res. 2000 Aug 18; 87(4): 275-81. 
[19] Tan HL, Kupershmidt S, Zhang R, Stepanovic S, Roden DM, Wilde AA, et al. A calcium sensor in the sodium channel modulates cardiac excitability. Nature. 2002 Jan 24; 415(6870): 442-7.

[20] Kim J, Ghosh S, Liu H, Tateyama M, Kass RS, Pitt GS. Calmodulin mediates Ca2+ sensitivity of sodium channels. J Biol Chem. 2004 Oct 22; 279(43): 45004-12.

[21] Wagner S, Maier LS. Modulation of cardiac $\mathrm{Na}(+)$ and $\mathrm{Ca}(2+)$ currents by $\mathrm{CaM}$ and CaMKII. J Cardiovasc Electrophysiol. 2006 May; 17 Suppl 1: S26-S33.

[22] Maltsev VA, Sabbah HN, Higgins RS, Silverman N, Lesch M, Undrovinas AI. Novel, ultraslow inactivating sodium current in human ventricular cardiomyocytes. Circulation. 1998 Dec 8; 98(23): 2545-52.

[23] Altamirano J, Bers DM. Effect of intracellular Ca2+ and action potential duration on L-type $\mathrm{Ca} 2+$ channel inactivation and recovery from inactivation in rabbit cardiac myocytes. Am J Physiol Heart Circ Physiol. 2007 Jul; 293(1): H563-73.

[24] Han DY, Minobe E, Wang WY, Guo F, Xu JJ, Hao LY, et al. Calmodulin- and $\mathrm{Ca} 2+$-dependent facilitation and inactivation of the Cav1.2 $\mathrm{Ca} 2+$ channels in guinea-pig ventricular myocytes. J Pharmacol Sci. 112(3): 310-9.

[25] Qi X, Yeh YH, Chartier D, Xiao L, Tsuji Y, Brundel BJ, et al. The calcium/calmodulin/kinase system and arrhythmogenic afterdepolarizations in bradycardiarelated acquired long-QT syndrome. Circ Arrhythm Electrophysiol. 2009 Jun; 2(3): 295304.

[26] Sag CM, Wadsack DP, Khabbazzadeh S, Abesser M, Grefe C, Neumann K, et al. Calcium/calmodulin-dependent protein kinase II contributes to cardiac arrhythmogenesis in heart failure. Circ Heart Fail. 2009 Nov; 2(6): 664-75.

[27] Xu Y, Tuteja D, Zhang Z, Xu D, Zhang Y, Rodriguez J, et al. Molecular identification and functional roles of a $\mathrm{Ca}(2+)$-activated $\mathrm{K}+$ channel in human and mouse hearts. J Biol Chem. 2003 Dec 5; 278(49): 49085-94.

[28] Zygmunt AC. Intracellular calcium activates a chloride current in canine ventricular myocytes. Am J Physiol. 1994 Nov; 267(5 Pt 2): H1984-95.

[29] Matsuura H, Ehara T. Activation of chloride current by purinergic stimulation in guinea pig heart cells. Circ Res. 1992 Apr; 70(4): 851-5.

[30] Hiraoka M, Kawano S, Hirano Y, Furukawa T. Role of cardiac chloride currents in changes in action potential characteristics and arrhythmias. Cardiovasc Res. 1998 Oct; 40(1): 23-33.

[31] Verkerk AO, Tan HL, Kirkels JH, Ravesloot JH. Role of Ca2+-activated Clcurrent during proarrhythmic early afterdepolarizations in sheep and human ventricular myocytes. Acta Physiol Scand. 2003 Oct; 179(2): 143-8.

[32] Garcia-Calvo M, Knaus HG, McManus OB, Giangiacomo KM, Kaczorowski GJ, Garcia ML. Purification and reconstitution of the high-conductance, calcium-activated potassium channel from tracheal smooth muscle. J Biol Chem. 1994 Jan 7; 269(1): 676-82.

[33] Meera P, Wallner M, Song M, Toro L. Large conductance voltage- and calciumdependent $\mathrm{K}+$ channel, a distinct member of voltage-dependent ion channels with seven $\mathrm{N}$ terminal transmembrane segments (S0-S6), an extracellular $\mathrm{N}$ terminus, and an intracellular (S9-S10) C terminus. Proc Natl Acad Sci U S A. 1997 Dec 9; 94(25): 1406671.

[34] Joiner WJ, Tang MD, Wang LY, Dworetzky SI, Boissard CG, Gan L, et al. Formation of intermediate-conductance calcium-activated potassium channels by interaction of Slack and Slo subunits. Nat Neurosci. 1998 Oct; 1(6): 462-9.

[35] Kohler M, Hirschberg B, Bond CT, Kinzie JM, Marrion NV, Maylie J, et al. Smallconductance, calcium-activated potassium channels from mammalian brain. Science. 1996 Sep 20; 273(5282): 1709-14. 
[36] Lu J, Xu XH, Wang XL. [Effect of KB-R7943 on Na(+)-Ca2+ exchange current in guinea pig ventricular myocytes]. Yao Xue Xue Bao. 2001 Jan; 36(1): 25-8.

[37] Tessier S, Karczewski P, Krause EG, Pansard Y, Acar C, Lang-Lazdunski M, et al. Regulation of the transient outward $\mathrm{K}(+)$ current by $\mathrm{Ca}(2+) /$ calmodulin-dependent protein kinases II in human atrial myocytes. Circ Res. 1999 Oct 29; 85(9): 810-9.

[38] Roeper J, Lorra C, Pongs O. Frequency-dependent inactivation of mammalian Atype $\mathrm{K}+$ channel $\mathrm{KV} 1.4$ regulated by $\mathrm{Ca} 2+/$ calmodulin-dependent protein kinase. $\mathrm{J}$ Neurosci. 1997 May 15; 17(10): 3379-91.

[39] Sergeant GP, Ohya S, Reihill JA, Perrino BA, Amberg GC, Imaizumi Y, et al. Regulation of Kv4.3 currents by $\mathrm{Ca} 2+/$ calmodulin-dependent protein kinase II. Am J Physiol Cell Physiol. 2005 Feb; 288(2): C304-13.

[40] Bassani RA. Transient outward potassium current and $\mathrm{Ca} 2+$ homeostasis in the heart: beyond the action potential. Braz J Med Biol Res. 2006 Mar; 39(3): 393-403.

[41] Apkon M, Nerbonne JM. Alpha 1-adrenergic agonists selectively suppress voltagedependent K+ current in rat ventricular myocytes. Proc Natl Acad Sci U S A. 1988 Nov; 85(22): 8756-60.

[42] Cui J, Melman Y, Palma E, Fishman GI, McDonald TV. Cyclic AMP regulates the HERG K(+) channel by dual pathways. Curr Biol. 2000 Jun 1; 10(11): 671-4.

[43] Kiehn J, Thomas D, Karle CA, Schols W, Kubler W. Inhibitory effects of the class III antiarrhythmic drug amiodarone on cloned HERG potassium channels. Naunyn Schmiedebergs Arch Pharmacol. 1999 Mar; 359(3): 212-9.

[44] Kiehn J. Regulation of the cardiac repolarizing HERG potassium channel by protein kinase A. Trends Cardiovasc Med. 2000 Jul; 10(5): 205-9.

[45] Lei M, Brown HF, Terrar DA. Modulation of delayed rectifier potassium current, $\mathrm{iK}$, by isoprenaline in rabbit isolated pacemaker cells. Exp Physiol. 2000 Jan; 85(1): 27-35. [46] Harmati G, Banyasz T, Barandi L, Szentandrassy N, Horvath B, Szabo G, et al. Effects of beta-adrenoceptor stimulation on delayed rectifier $\mathrm{K}(+)$ currents in canine ventricular cardiomyocytes. Br J Pharmacol. Feb; 162(4): 890-6.

[47] Thomas D, Zhang W, Wu K, Wimmer AB, Gut B, Wendt-Nordahl G, et al. Regulation of HERG potassium channel activation by protein kinase $\mathrm{C}$ independent of direct phosphorylation of the channel protein. Cardiovasc Res. 2003 Jul 1; 59(1): 14-26.

[48] Heath BM, Terrar DA. Protein kinase C enhances the rapidly activating delayed rectifier potassium current, $\mathrm{IKr}$, through a reduction in C-type inactivation in guinea-pig ventricular myocytes. J Physiol. 2000 Feb 1; 522 Pt 3: 391-402.

[49] Tohse N, Kameyama M, Irisawa $\mathrm{H}$. Intracellular $\mathrm{Ca} 2+$ and protein kinase $\mathrm{C}$ modulate $\mathrm{K}+$ current in guinea pig heart cells. Am J Physiol. $1987 \mathrm{Nov}$; 253(5 Pt 2): H1321-4.

[50] Walsh KB, Kass RS. Distinct voltage-dependent regulation of a heart-delayed IK by protein kinases A and C. Am J Physiol. 1991 Dec; 261(6 Pt 1): C1081-90.

[51] Tristani-Firouzi M, Sanguinetti MC. Structural determinants and biophysical properties of HERG and KCNQ1 channel gating. J Mol Cell Cardiol. 2003 Jan; 35(1): $27-$ 35 .

[52] Washizuka T, Horie M, Watanuki M, Sasayama S. Endothelin-1 inhibits the slow component of cardiac delayed rectifier $\mathrm{K}+$ currents via a pertussis toxin-sensitive mechanism. Circ Res. 1997 Aug; 81(2): 211-8.

[53] Lopatin AN, Nichols CG. Inward rectifiers in the heart: an update on I(K1). J Mol Cell Cardiol. 2001 Apr; 33(4): 625-38.

[54] Li N, Timofeyev V, Tuteja D, Xu D, Lu L, Zhang Q, et al. Ablation of a Ca2+activated $\mathrm{K}+$ channel (SK2 channel) results in action potential prolongation in atrial myocytes and atrial fibrillation. J Physiol. 2009 Mar 1; 587(Pt 5): 1087-100. 
[55] Zhang Q, Timofeyev V, Lu L, Li N, Singapuri A, Long MK, et al. Functional roles of a Ca2+-activated $\mathrm{K}+$ channel in atrioventricular nodes. Circ Res. 2008 Feb 29; 102(4): 465-71.

[56] Nagy N, Szuts V, Horvath Z, Seprenyi G, Farkas AS, Acsai K, et al. Does smallconductance calcium-activated potassium channel contribute to cardiac repolarization? $\mathrm{J}$ Mol Cell Cardiol. 2009 Nov; 47(5): 656-63.

[57] Weber CR, Piacentino V, 3rd, Ginsburg KS, Houser SR, Bers DM. Na(+)-Ca(2+) exchange current and submembrane $[\mathrm{Ca}(2+)]$ during the cardiac action potential. Circ Res. 2002 Feb 8; 90(2): 182-9.

[58] Birinyi P, Toth A, Jona I, Acsai K, Almassy J, Nagy N, et al. The $\mathrm{Na}+\mathrm{Ca} 2+$ exchange blocker SEA0400 fails to enhance cytosolic Ca2+ transient and contractility in canine ventricular cardiomyocytes. Cardiovasc Res. 2008 Jun 1; 78(3): 476-84.

[59] Farkas AS, Makra P, Csik N, Orosz S, Shattock MJ, Fulop F, et al. The role of the $\mathrm{Na}+\mathrm{Ca} 2+$ exchanger, $\mathrm{I}(\mathrm{Na})$ and $\mathrm{I}(\mathrm{CaL})$ in the genesis of dofetilide-induced torsades de pointes in isolated, AV-blocked rabbit hearts. Br J Pharmacol. 2009 Mar; 156(6): 920-32.

[60] Acsai K, Kun A, Farkas AS, Fulop F, Nagy N, Balazs M, et al. Effect of partial blockade of the $\mathrm{Na}(+) / \mathrm{Ca}(2+)$-exchanger on $\mathrm{Ca}(2+)$ handling in isolated rat ventricular myocytes. Eur J Pharmacol. 2007 Dec 8; 576(1-3): 1-6.

[61] Farkas AS, Acsai K, Nagy N, Toth A, Fulop F, Seprenyi G, et al. $\mathrm{Na}(+) / \mathrm{Ca}(2+)$ exchanger inhibition exerts a positive inotropic effect in the rat heart, but fails to influence the contractility of the rabbit heart. Br J Pharmacol. 2008 May; 154(1): 93-104.

[62] Matsuda H, Cruz Jdos S. Voltage-dependent block by internal $\mathrm{Ca} 2+$ ions of inwardly rectifying $\mathrm{K}+$ channels in guinea-pig ventricular cells. J Physiol. 1993 Oct; 470: 295-311.

[63] Matsuda H, Saigusa A, Irisawa H. Ohmic conductance through the inwardly rectifying $\mathrm{K}$ channel and blocking by internal Mg2+. Nature. $1987 \mathrm{Jan}$ 8-14; 325(7000): 156-9.

[64] Mazzanti M, DeFelice LJ. Ca modulates outward current through IK1 channels. J Membr Biol. 1990 Jun; 116(1): 41-5.

[65] Delmar M, Ibarra J, Davidenko J, Lorente P, Jalife J. Dynamics of the background outward current of single guinea pig ventricular myocytes. Ionic mechanisms of hysteresis in cardiac cells. Circ Res. 1991 Nov; 69(5): 1316-26.

[66] Isenberg G. Cardiac Purkinje fibres: [Ca2+]i controls the potassium permeability via the conductance components gK1 and gK2. Pflugers Arch. 1977 Oct 19; 371(1-2): 7785.

[67] Kass RS, Tsien RW. Control of action potential duration by calcium ions in cardiac Purkinje fibers. J Gen Physiol. 1976 May; 67(5): 599-617.

[68] Piao L, Li J, McLerie M, Lopatin AN. Cardiac IK1 underlies early action potential shortening during hypoxia in the mouse heart. J Mol Cell Cardiol. 2007 Jul; 43(1): 27-38.

[69] Coraboeuf E. Ionic basis of electrical activity in cardiac tissues. Am J Physiol. 1978 Feb; 234(2): H101-16.

[70] Zaza A, Rocchetti M, Brioschi A, Cantadori A, Ferroni A. Dynamic Ca2+-induced inward rectification of $\mathrm{K}+$ current during the ventricular action potential. Circ Res. 1998 May 18; 82(9): 947-56.

[71] Fauconnier J, Lacampagne A, Rauzier JM, Vassort G, Richard S. Ca2+-dependent reduction of IK1 in rat ventricular cells: a novel paradigm for arrhythmia in heart failure? Cardiovasc Res. 2005 Nov 1; 68(2): 204-12.

[72] Wagner S, Hacker E, Grandi E, Weber SL, Dybkova N, Sossalla S, et al. $\mathrm{Ca} /$ calmodulin kinase II differentially modulates potassium currents. Circ Arrhythm Electrophysiol. 2009 Jun; 2(3): 285-94. 
[73] Carmeliet E. Cardiac ionic currents and acute ischemia: from channels to arrhythmias. Physiol Rev. 1999 Jul; 79(3): 917-1017.

[74] Ruiz-Petrich E, de Lorenzi F, Chartier D. Role of the inward rectifier IK1 in the myocardial response to hypoxia. Cardiovasc Res. 1991 Jan; 25(1): 17-26.

[75] Muramatsu H, Sato R, Okumura H. Early increase in $\mathrm{K}+$ conductance during metabolic inhibition by cyanide in guinea pig ventricular myocytes. Nippon Ika Daigaku Zasshi. 1990 Aug; 57(4): 308-21.

[76] Park WS, Han J, Kim N, Ko JH, Kim SJ, Earm YE. Activation of inward rectifier $\mathrm{K}+$ channels by hypoxia in rabbit coronary arterial smooth muscle cells. Am J Physiol Heart Circ Physiol. 2005 Dec; 289(6): H2461-7.

[77] Banyasz T, Horvath B, Virag L, Barandi L, Szentandrassy N, Harmati G, et al. Reverse rate dependency is an intrinsic property of canine cardiac preparations. Cardiovasc Res. 2009 Nov 1; 84(2): 237-44. 


\section{ACKNOWLEDGEMENT}

I am especially thankful to my supervisors András Tóth, $\mathbf{P h D}$, for introducing me to the cellular fluorescent techniques, and for providing me the opportunity to work in the optical laboratory, and to Professor András Varró, MD, DSc, for his permanent support and personal guidance, at the Department of Pharmacology and Pharmacotherapy and at the Division of Cardiovascular Pharmacology. Their personal guidance and the helpful discussions were exceptionally useful during my work and allowed me to develop the critical thinking needed in the scientific field.

I am very grateful to Professor Julius Gy. Papp, MD, DSc, member of the Hungarian Academy of Sciences, for his permanent support, advices, criticism, and suggestions.

I wish to thank my colleagues, Péter Nánási MD, DSc; Norbert Szentandrássy PhD; Károly Acsai PhD; Attila S. Farkas MD, PhD; László Virág PhD; Norbert Jost PhD; Zoltán Márton PhD; Zsófia Kohajda MSc; János Prorok MSc; Anita Kormos MSc; and to Judit Szepesi MSc for their continuous support and help in my work. I am also very grateful to Ms. Zsuzsanna Sebök for the excellent technical assistance.

I am also very thankful to late Miklós Németh PhD, my very first supervisor, who introduced me into cardiac cellular electrophysiology, as well, as to Ms. Zsuzsanna Molnár, Gyula Horváth, and Gábor Girst for their helpful technical assistance.

Finally, I wish to thank, and dedicate this thesis to my whole family and to my friends for their love, help and encouragement. 